\title{
REVIEW
}

\section{The APOBEC3 genes and their role in cancer: insights from human papillomavirus}

\author{
Nicola J Smith and Tim R Fenton \\ School of Biosciences, University of Kent, Canterbury, Kent, UK \\ Correspondence should be addressed to T R Fenton: t.fenton@kent.ac.uk
}

\begin{abstract}
The interaction between human papillomaviruses (HPV) and the apolipoprotein-B mRNA-editing catalytic polypeptide-like (APOBEC)3 (A3) genes has garnered increasing attention in recent years, with considerable efforts focused on understanding their apparent roles in both viral editing and in HPV-driven carcinogenesis. Here, we review these developments and highlight several outstanding questions in the field. We consider whether editing of the virus and mutagenesis of the host are linked or whether both are essentially separate events, coincidentally mediated by a common or distinct A3 enzymes. We discuss the viral mechanisms and cellular signalling pathways implicated in A3 induction in virally infected cells and examine which of the A3 enzymes might play the major role in HPV-associated carcinogenesis and in the development of therapeutic resistance. We consider the parallels between A3 induction in HPV-infected cells and what might be causing aberrant A3 activity in HPV-independent cancers such as those arising in the bladder, lung and breast. Finally, we discuss the implications of ongoing A3 activity in tumours under treatment and the therapeutic opportunities that this may present.
\end{abstract}

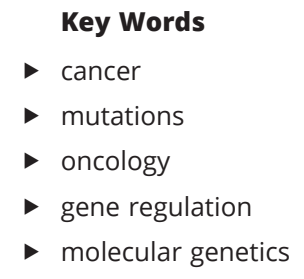

Journal of Molecular Endocrinology (2019) 62, R269-R287

\section{Introduction}

A link between sexual contact and cervical cancer was first reported in 1842, by the Italian physician, Rigoni-Stern (Rigoni-Stern 1842) yet the role of human papillomaviruses (HPVs) as the incriminating infectious agent was not substantiated until the 1970s; at which time, intranuclear papillomavirus particles were found within koilocytic epithelial cells of cervical condylomatosis (Della Torre et al. 1978, Hills \& Laverty 1979). By 1983, the DNA of HPV-16 and HPV-18 had been successfully isolated from cervical cancer biopsies (Dürst et al. 1983, Boshart et al. 1984), but the many molecular mechanisms by which these viruses cause cancer continue to be elucidated.

HPVs are small, non-enveloped DNA viruses, consisting of an $8 \mathrm{~kb}$ circular genome (Fig. 1A) encased in a viral capsid. There are over 200 different genotypes with tropisms for stem cells in the basal layer of either cutaneous or mucosal epithelia, in which the viral life cycle is tightly linked to and dependent upon keratinocyte differentiation (Fig. 1B). The HPV genome consists of six early genes responsible for viral genome maintenance and amplification and two late genes (L1 and L2) which encode the viral capsid proteins and are expressed in terminally differentiated keratinocytes immediately prior to host cell death and release of virions (for detailed reviews see Doorbar et al. 2015, McBride 2017). Infection is typically either asymptomatic or associated with benign warts. At least 14 HPV types however (including HPV-16 and HPV-18), are carcinogenic, and these 'high-risk' (HR-HPV) types cause human cancers in the mucosal epithelia of several sites, including 
A
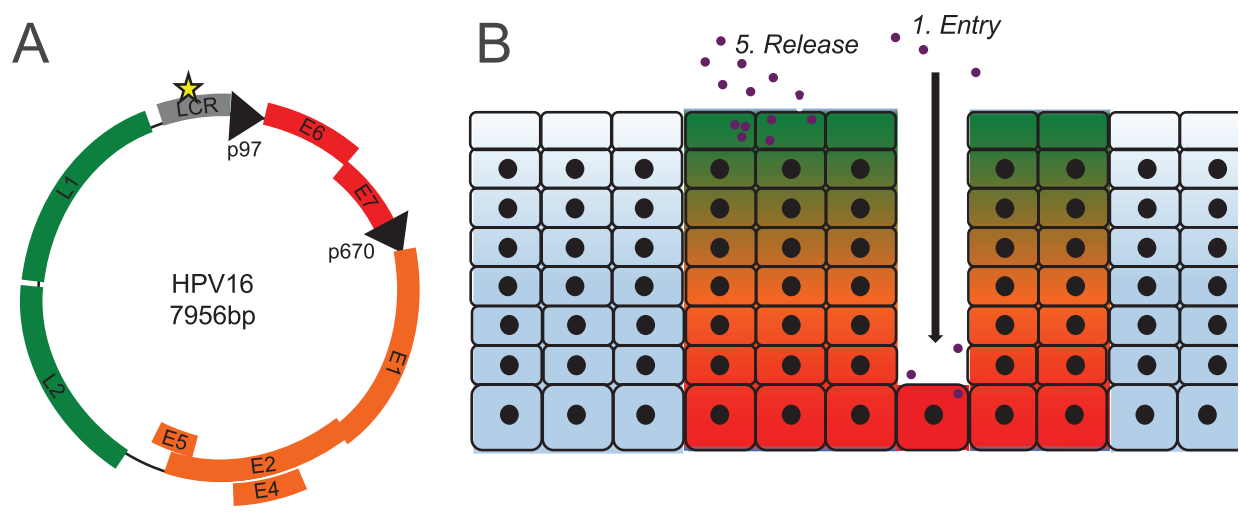

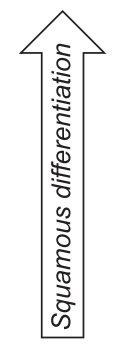

4. Virus assembly $(L 1, L 2)$

3. Genome amplification (E1, E2, E4, E5)

2. Infection, genome maintenance $(E 6, E 7)$

Origin of replication

\section{Figure 1}

HPV16 genome organisation and replication cycle. (A) The HPV16 genome is shown, with the E6 and E7 oncogenes represented in red, the remaining early genes in orange and the genes encoding the major (L1) and minor (L2) capsid proteins shown in green. The origin of replication in the long control region (yellow star) appears to be most heavily edited by one or more human A3 enzymes. (B) The productive HPV replication cycle in stratified epithelia: (1) Virus entry (purple dots) to the basal layer at the site of an abrasion (for example in the stratified epithelium of the ectocervix) is shown; (2) infection of basal cells is followed by expression of E6 and E7 (red), leading to host cell cycle entry and initial replication of the HPV genome during S-phase; (3) cells in the mid-layer enter differentiation and are held in an extended G2 phase during which HPV genomes are amplified by the host cell homologydirected repair machinery (orange colour represents expression of HPV early genes E1, E2, E4, E5); (4) virus assembly occurs in the upper layers, in which early gene expression is replaced by L1 and L2 (green) during terminal differentiation and enucleation of host keratinocytes; (5) viral particles (purple dots) are released from the epithelium (adapted from Doorbar et al. 2012, Lechner \& Fenton 2016).

the cervix, vulva, vagina, penis, anus and oropharynx (tonsils and tongue base). The vast majority of HR-HPV infections are cleared naturally within 12-18 months by the host immune system (Richardson et al. 2003, Bodily \& Laimins 2011), yet globally, HPV infection accounts for over 600,000 cancers (90\% of which are cervical cancers) and 250,000 deaths per year (de Martel et al. 2017). The complex biology underlying HPV-associated carcinogenesis is the subject of many detailed reviews (e.g. Bodily \& Laimins 2011, Doorbar et al. 2015, Lechner $\&$ Fenton 2016). Here we will focus on the emerging role that one or more of the apolipoprotein-B mRNAediting catalytic polypeptide-like-3 (APOBEC3 or A3) family of innate immune response genes appear to play in this process, including the generation of somatic alterations to the host genome that in addition to viral oncoprotein expression are required for HPV-associated carcinogenesis.

\section{Current model of HPV-induced carcinogenesis}

Papillomaviruses rely on host DNA polymerases and the DNA damage response for replication and amplification of their genomes and must therefore induce cell cycle entry upon infection - a process which is driven by two viral early genes, E6 and E7 (reviewed in Doorbar et al. 2015, McBride 2017). E6 and E7 from high-risk HPV types
(HR-E6/HR-E7, also known as the HPV oncogenes) harbour several activities not shared by their low-risk homologues, which appear to be important for carcinogenesis and may serve to trigger the mutagenic activity of APOBEC3 (A3) proteins seen in HPV-associated cancers. In particular, the induction of replication stress, host DNA repair responses and downregulation of the $\mathrm{pRB}$ and p53 tumour suppressors (Munger \& Jones 2015) are key activities of HR-E6 and E7 that will be discussed in this context. During productive infection, the expression of E6 and E7 is restricted to the basal and parabasal layers of the epithelium and at later stages is repressed by the viral E2 protein but in a small fraction of HR-HPV infections, the virus persists and cells with increased E6/E7 expression gain a selective growth advantage, populating the upper epithelial layers. Differentiation of these cells is blocked, resulting in loss of additional viral gene expression and exit from the productive life cycle. In the cervix, this can be observed in the transition from early cervical intraepithelial neoplasia (CIN1), to precancerous CIN2/3 lesions that forms the basis of cervical cancer screening. In CIN3 lesions and invasive carcinoma, integration of the virus into the host genome and loss of viral episomes is commonly observed, with a selection in vivo for clones in which integration has disrupted the E2 gene, permitting further increases in E6/E7 expression (Bodily \& Laimins 2011, Doorbar et al. 2015). 


\section{The $\mathrm{A} 3$ genes and somatic mutagenesis in cancer}

The rate at which somatic mutations accumulate in cells is governed both by the rate at which DNA damage occurs and by the fidelity with which it is repaired or damaged cells are eliminated by apoptosis. Loss of p53 could explain the persistence of cells carrying DNA damage, but which mutational processes generate the mutations in HPVinfected cells and does HPV increase the rate at which DNA damage occurs? The wealth of somatic mutation data generated by large-scale cancer genomic efforts such as The Cancer Genome Atlas (TCGA) project and the International Cancer Genome Consortium (ICGC) has recently enabled the identification of mutational signatures - distinctive patterns that can reveal the mutational processes operational in different tumours (Nik-Zainal et al. 2012a, Alexandrov et al. 2013a,b). As might be expected, skin cancer genomes are dominated by CC>TT mutations consistent with those caused by ultraviolet light in experimental systems, while cancers associated with tobacco smoking display a mutational signature $(\mathrm{G}>\mathrm{T}$ and GG $>$ TT mutations) implicating tobacco carcinogens such as benzo(a)pyrene. In both cases, the mutation signatures display a transcriptional strand bias that is consistent with the known role for transcription-coupled nucleotide excision repair in resolving such lesions (Alexandrov et al. 2013a). Other mutational signatures arise from specific defects in the pathways responsible for repairing DNA damage; at least four signatures have been linked to defects in mismatch repair for instance, while defects in double-strand break repair by homologous recombination give rise to a signature observed in tumours harbouring $B R C A 1$ or BRCA2 mutations (https://cancer.sanger.ac.uk/ cosmic/signatures, Forbes et al. 2017). The mutational signatures observed in tumour samples (or indeed in healthy tissue) are therefore shaped both by the processes that have caused damage to the DNA during the lifetime of the individual and by the pathways (or defects therein) responsible for repairing that damage.

Strikingly, cancers in several tissues, including breast, lung, bladder, cervix and head and neck frequently display two closely related signatures characterized by $\mathrm{C}>\mathrm{T}$ transitions and $\mathrm{C}>\mathrm{G}$ transversions at $\mathrm{TpC}$ dinucleotides that have been attributed to the deoxycytidine deamination activity of one or more APOBEC enzymes (Alexandrov et al. 2013a, Burns et al. 2013a,b, Roberts et al. 2013, Taylor et al. 2013). Humans possess 11 APOBEC genes, with physiological roles including antibody diversification (activation-induced cytidine deaminase,
AICDA), cellular mRNA editing (APOBEC1) and inhibition of exogenous virus and endogenous retroelement replication, which are mediated by members of the 7-gene APOBEC3 (A3) family, (Fig. 2), reviewed in (Holmes et al. 2007, Conticello 2008, Harris \& Dudley 2015). Soon after the cloning of $A P O B E C 1$, it was shown that liverspecific over-expression in transgenic mice or rabbits caused hepatocellular carcinoma (Yamanaka et al. 1995). The subsequent demonstration that APOBEC1, several A3 enzymes and AICDA (AID) could deaminate ssDNA in addition to RNA (Harris et al. 2002, Petersen-Mahrt et al. 2002), together with the finding that transgenic AICDA mice were also cancer prone (Okazaki et al. 2003) suggested a potential role for mutagenic APOBEC/AID activity in the development of human cancers - a hypothesis that awaited large-scale testing until the advent of nextgeneration sequencing (NGS) and the detection of the aforementioned mutational signatures in tumour exomes. APOBEC 1 and several of the closely related A3 enzymes (A3A, B, C, D, F and H) display a preference for deamination of TpC sites in ssDNA in vitro that is consistent with the TpC mutational signatures observed in cancer genomes, with gene expression analysis and loss-of-function experiments in breast cancer cell lines suggesting a prominent role for A3B (Burns et al. 2013a). Distinct A3G and AID mutational signatures have also been detected across a wide range of cancer types (Rogozin et al. 2019) but for the purposes of this review, we focus on the TpC signatures, henceforth referred to as APOBEC associated. Analyses of cancer genome sequencing data and studies in cells overexpressing $\mathrm{A} 3 \mathrm{~A}$ or $\mathrm{A} 3 \mathrm{~B}$ suggest the major exposure of ssDNA substrate for A3 activity in tumour cells arises on the lagging strand during DNA replication, presumably as a result of replication fork stalling due to replication stress (Green et al. 2016, Haradhvala et al. 2016, Hoopes et al. 2016, Morganella et al. 2016, Seplyarskiy et al. 2016). Unlike other mutational signatures, A3-mediated mutations are frequently enriched in early-replicating regions of the genome, although interestingly this effect is more pronounced in lung and bladder cancer exomes from TCGA than in cervix and is not apparent in head and neck squamous cell carcinoma (HNSCC) (Kazanov et al. 2015).

The strong enrichment of the APOBEC signature in cervical cancer exomes (Alexandrov et al. 2013a, Burns et al. 2013b, Roberts et al. 2013), together with previous evidence for A3 editing of HPV genomes in plantar warts and precancerous cervical lesions (Vartanian et al. 2008) suggested that the presence of HPV in cells might somehow induce or potentiate A3 activity, damaging the 


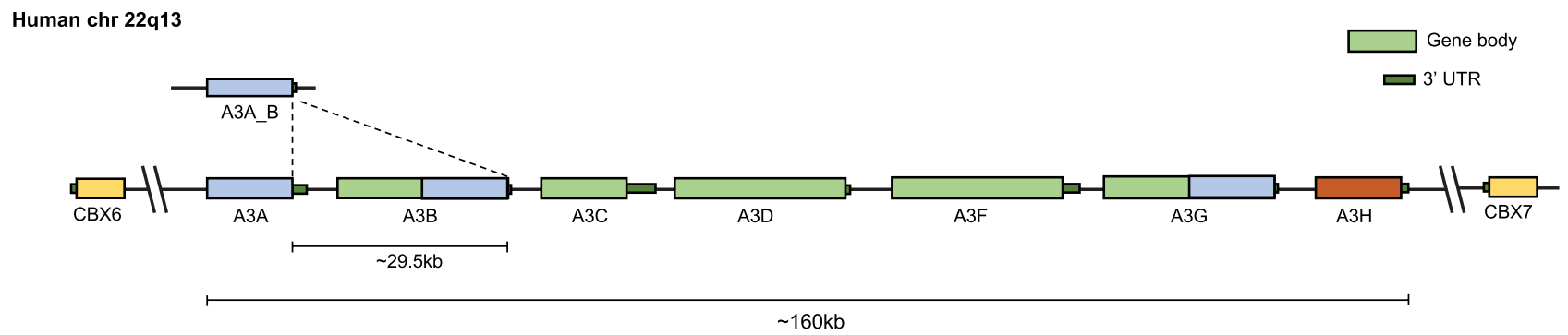

Mouse chr 15

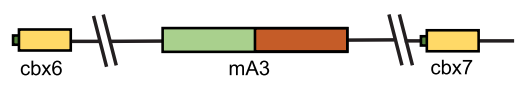

\section{Figure 2}

Schematic representation of the APOBEC3 locus in humans and mice. Approximate relative lengths of the open-reading frames (ORFs) and 3'-untranslated regions (UTRs) of each gene are shown and homologous domains are represented in common colours. The A3A_B deletion polymorphism is also represented, showing the fusion gene in which the A3A ORF is fused to the A3B 3' UTR (relative 3' UTR sizes from UCSC Genome Browser (https://genome.ucsc.edu/)).

host genome and resulting in the observed enrichment of these mutational signatures in HPV-associated cancers (Kuong \& Loeb 2013). Having identified A3B among a list of genes that are consistently upregulated in HPVassociated malignancies irrespective of anatomic site, we tested for such an association in HNSCC, observing increased $A P O B E C 3 B$ expression and enrichment of the APOBEC mutational signature in the $\sim 15 \%$ of HPV-associated cases in the CGA HNSCC cohort, the majority of which are oropharyngeal tumours. We also noted a distinctive pattern of APOBEC signature mutations in exon 9 of the PIK3CA proto-oncogene in $\mathrm{HPV}+\mathrm{HNSCC}$ and in other cancer types displaying the APOBEC mutational signature, thus directly implicating APOBEC activity in the generation of oncogenic driver events (Henderson et al. 2014, Chakravarthy et al. 2016). These findings were subsequently confirmed by TCGA (The Cancer Genome Atlas Network 2015) and by recent analyses of expanded (Gillison et al. 2019) and independent (Qin et al. 2018) HPV+ HNSCC cohorts. In a separate study published the same year, Vieira and colleagues also reported the enrichment of APOBEC signature mutations in HPV+ CGA HNSCCs and showed induction of A3B mRNA expression and deaminase activity in keratinocytes by E6 from the two major highrisk HPV types, HPV16 and HPV18 (Vieira et al. 2014). Consistent with these observations, APOBEC signature mutations are also enriched in $\mathrm{HPV}+$ penile carcinoma exomes, with those tumours harbouring higher viral loads displaying greater enrichment (Feber et al. 2016). In further work, Pyeon and colleagues noted upregulation of both $\mathrm{A} 3 \mathrm{~A}$ and $\mathrm{A} 3 \mathrm{~B}$ expression in precancerous cervical lesions and demonstrated their induction by $\mathrm{E} 7 \mathrm{in}$ keratinocytes (Warren et al. 2015a). The same group have since shown that E7 from HR-HPV types can stabilize A3A protein by blocking its polyubiquitination by cullinRING-based E3 ubiquitin ligase complexes (Fig. 3); thus, HPVs appear to modulate A3 expression at multiple levels (Westrich et al. 2018). Also of note are roles that A3 enzymes may play in HPV-associated cancer that are independent of their mutagenic activity against the host genome. Intriguingly, Periyasamy and colleagues have shown that $\mathrm{A} 3 \mathrm{~B}$ associates with the oestrogen receptor (ER) in breast cancer cell lines and co-activates ER target genes (Periyasamy et al. 2015). The proposed mechanism involves deamination of promoter sites by A3B, leading to recruitment of DNA repair proteins and local chromatin remodelling. The cervical epithelium is also an oestrogen-responsive tissue; indeed, HPV E6/

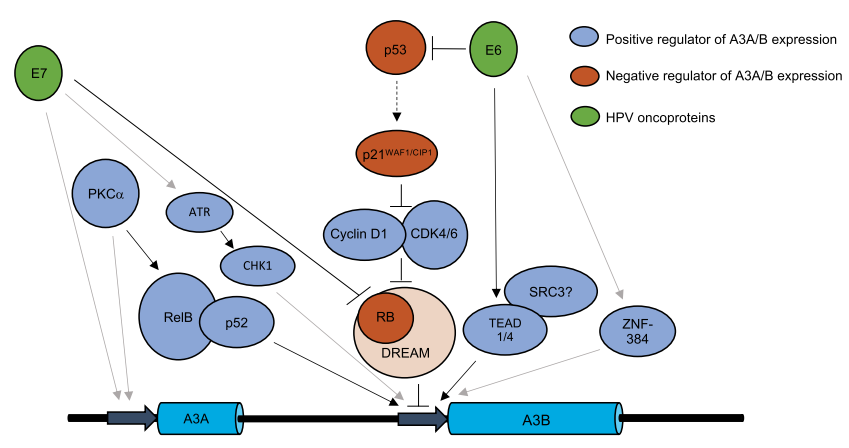

Figure 3

Regulation of $A 3 A$ and $A 3 B$ gene expression by several cellular pathways impacted by HPV E6 or E7. Pathways implicated in regulation of A3A and A3B transcription are shown, grey arrows indicate proposed regulation via unknown intermediates, dashed lines represent transcriptional regulation of the gene encoding the target protein, see main text for details. 
E7-driven cervical cancer development in transgenic mice can be promoted by oestradiol infusion over several months (Brake \& Lambert 2005). It is possible then that A3B could also fuel cervical carcinogenesis via this non-mutagenic but nonetheless deaminase-dependent transcriptional activity.

\section{A3 genes and viral restriction}

Numerous studies indicate an important role for A3 genes in innate immunity, and it is presumably an aberrant triggering and/or regulation of this response that results in the somatic mutagenesis observed in cancer. Coincident with the cloning of the human A3 genes (Jarmuz et al. 2002) and the discovery that they can deaminate ssDNA (Harris et al. 2002), a series of seminal papers demonstrated a role for A3G (originally termed CEM-15) in HIV-1 restriction (Sheehy et al. 2002) and revealed a deaminase-dependent mechanism involving extensive editing of the first-strand cDNA and resulting in G-to-A mutations on the positive strand (Harris et al. 2003, Mangeat et al. 2003, Zhang et al. 2003), although A3G also exerts deaminase-independent antiviral activity against HIV-1 (Newman et al. 2005). Other A3 enzymes, notably A3F and A3DE, also appear to function in HIV-1 restriction in lymphocytes, while A3A is required in monocytes - a cell type in which it is highly expressed. Unlike A3G, however, it is not incorporated into HIV virions and may act together with A3G in this capacity (reviewed in (Chiu \& Greene 2008).

One major obstacle to the study of A3 function in vivo is the greatly increased complexity of the A3 locus in primates compared with model organisms. Rodents possess only one A3 gene: a double-domain enzyme most closely related to A3G (Conticello et al. 2005), thus dissecting the roles of individual A3 genes in an organismal context remains a challenge. Use of murine A3 (mA3)-knockout mice (which are viable and fertile) has clearly demonstrated that it functions as a cellautonomous restriction factor for exogenous murine retroviruses including mouse mammary tumour virus (MMTV), Friend murine leukaemia virus (MLV) and to a lesser extent, Moloney murine leukaemia virus (MoMLV), with recent work suggesting a primarily deaminaseindependent mechanism (Okeoma et al. 2007, 2009, Stavrou et al. 2018).

Several A3s including A3A also inhibit Long Interspersed Element-1 (LINE-1) retrotransposition, through a mechanism that appears to involve deamination of single-stranded cDNA exposed by the action of RNase-H upon RNA/DNA hybrids (Richardson et al. 2014). Indeed, it appears likely that the activity against endogenous retroviruses drove the expansion of the A3 family seen in primates and other mammals, since it predates the appearance of lentiviruses (Conticello et al. 2005, Chiu \& Greene 2008). It was recently proposed that this activity against retroelements could ameliorate the loss of LINE1 silencing caused by E7 inhibition of RB1, thus providing a potential explanation for why HPV causes A3 upregulation (Wallace \& Münger 2018).

An activity against DNA viruses was first shown for $\mathrm{A} 3 \mathrm{~A}$, in studies demonstrating inhibition of adenoassociated virus replication through a deaminaseindependent mechanism (Chen et al. 2006, Narvaiza et al. 2009). These in vitro experiments were supported by a study in which a human A3A transgene (but not A3G) expressed in the mA3-knockout background reduced infectivity of a murine parvovirus without evidence of viral genome editing, while neither A3A nor A3G inhibited herpesvirus infection in this in vivo model (Nakaya et al. 2016). HPV pseudovirions produced in 293T cells overexpressing A3A or A3C displayed decreased infectivity, while A3A knockdown increased infectivity, suggesting these A3s may act as HPV restriction factors in vivo (Ahasan et al. 2015, Warren et al. 2015a), but the mechanism by which A3A inhibits HPV awaits full elucidation. Although the deaminase activity appears to be required, evidence of editing was not detected in HPV pseudovirion genomes from cells over expressing A3A, leading to the suggestion that its recently described RNA-editing activity may be responsible (Sharma et al. 2015, Warren et al. 2017). On the other hand, HPVs are subject to A3 editing in vivo, as first reported by Vartanian and colleagues (Vartanian et al. 2008), see below for detailed discussion. It appears that A3A and A3C may act on HPV at different levels, as cells expressing A3A contained reduced levels of encapsidated pseudovirions, while A3C was found to physically interact with the L1 viral capsid protein, potentially inhibiting infectivity by interfering with viral entry into target cells (Ahasan et al. 2015). Of note, several groups have reported cell cycle arrest upon transfection of $\mathrm{A} 3 \mathrm{~A}$ and have linked this to DNA damage caused by its deaminase activity against genomic DNA (Landry et al. 2011, Land et al. 2013, Mussil et al. 2013). Since HPV replication is dependent upon host cell transit through S-phase, it will be interesting to determine whether the restriction activity observed in vitro is due to a direct effect on the virus or whether it is an indirect consequence of an A3Amediated cell cycle arrest. 


\section{A3s as HPV editors?}

As discussed earlier, transient transfection experiments using HPV pseudovirions in 293FT cells suggested possible roles for $\mathrm{A} 3 \mathrm{~A}$ and $\mathrm{A} 3 \mathrm{C}$ in HPV restriction but did not implicate viral genome editing in this process. In W12, an HPV-16+ cell line originally derived from a low-grade CIN lesion (Stanley et al. 1989), over-expression of A3A or A3G did not reduce virus copy number but did result in editing of the $E 2$ gene, as detected by the highly sensitive 3D-PCR method originally used to demonstrate editing of the HPV-1a and HPV-16 LCRs in warts and precancerous cervical lesions, respectively (Vartanian et al. 2008, Wang et al. 2014). Editing was likewise detected upon treatment of W12 cells with IFN- $\beta$, which induced the expression of A3A, A3F and A3G (Wang et al. 2014). Editing of the HPV$16 \mathrm{E} 2$ gene in precancerous cervical lesions has also been demonstrated using 3D-PCR (Kukimoto et al. 2015), and these observations have since been supported by NGS of the entire HPV-16 genome, revealing the expected strandcoordinated $\mathrm{C}: \mathrm{G}>\mathrm{G}: \mathrm{A}$ transitions overrepresented at $\mathrm{TpC}$ sites throughout the early genes but enrichment within the LCR (Wakae et al. 2015). The authors speculate that enrichment for A3 editing in the LCR could result from increased exposure of ssDNA at the origin of replication and/or transcription from the p97 promoter both located in this region (Fig. 1). This study also reported A3A and $\mathrm{A} 3 \mathrm{C}$ to be the most abundant $\mathrm{A} 3$ transcripts in the one HPV-infected cervix examined, while A3B was expressed at much lower levels. It should be noted that the frequency of HPV editing detected in all these studies was significantly lower than that detected for other viruses known to be edited by A3s, such as HIV-1 or HBV (Wakae et al. 2015). Indeed, in the W12 cell system, it was necessary to block the repair of deaminated cytosines with an inhibitor of uracil-DNA glycosylase to reveal editing, even when using highly sensitive techniques such as 3D-PCR or NGS for detection (Wang et al. 2014).

Taken together, these studies suggest that if A3s are playing a role in HPV restriction in vivo, it is likely to be either much less effective than the response against viruses such as HIV-1 or that it proceeds via an editing-independent mechanism, as suggested by the pseudovirion studies (Ahasan et al. 2015, Warren et al. 2015a). Nevertheless, low-level HPV editing by A3s could still contribute to HPV pathology, by generating variation that could facilitate evasion of host-adaptive immune responses, analogous to the role that sublethal A3-mediated editing appears to play in HIV-1 immune escape (reviewed in Venkatesan et al. 2018).
Papillomaviruses hijack the host DNA repair machinery for the amplification stage of their replication cycle, specifically homologous recombination (recombinationdependent replication (RDR)), which allows very high fidelity viral replication consistent with the very slow rate of papillomavirus evolution; approximately $2 \times 10^{-8}$ nucleotide substitutions per site per year in the coding region (Rector et al. 2007, Sakakibara et al. 2013). Thus, unlike RNA viruses, in which low-fidelity replication generates considerable variation, editing, even at a low frequency likely represents an important source of papillomavirus variation. RDR occurs independently of host DNA replication, in an extended G2-like cell cycle phase that the virus maintains in differentiating keratinocytes and although this results in very high fidelity replication, depending on the precise mechanism, it may also involve the generation of long stretches of ssDNA (Sakakibara et al. 2013), thus potentially exposing the viral genome to A3 activity. Intriguingly, a recent analysis of cancer gene expression data has shown that A3B is co-expressed with multiple DNA damage response and G2/M-phase cell cycle genes, suggesting it might be induced in precisely this context ( $\mathrm{Ng}$ et al. 2019). Indeed, a recent study in which HPV was sequenced from 124 CIN lesions and 27 invasive cervical carcinomas supports a role for A3s in generating within-host sequence diversity as assessed by looking for minor variants (allele frequency of greater than $0.5 \%$ ) in NGS data, with the greatest proportion of A3 signature mutations observed in CIN1 lesions, suggesting this process is primarily acting during productive infection, when HPV is actively replicating (Hirose et al. 2018). As the authors of this study point out, editing of HPV at this point may be favoured by the exposure of ssDNA during viral replication but would also be consistent with a role for within-host editing in generating variation prior to viral release and subsequent inter-host transmission, and therefore, contributing to viral evolution. In this regard, A3 activity has been invoked as the cause of $\mathrm{TpC}$ dinucleotide depletion in the mucosal alpha-papillomaviruses, of which the HR-HPVs are examples (Warren et al. 2015b). This TpC depletion has primarily occurred at the third codon position in viral open-reading frames, as might be expected given the preservation of amino acid sequence permitted, meaning the A3 editing activity observed in current HPV genomes frequently affects the first or second codon positions, resulting in non-synonymous mutations (Hirose et al. 2018). Although such mutations would frequently be deleterious, those that do not compromise fitness could aid evasion of host adaptive immune responses by 
altering viral antigens and therefore undergo positive selection, at least within host. In tumours, the HPV sequence observed reflects not only the editing that has occurred but also the effect of selection against loss of (and possibly for enhancement of) host cell fitness. This purifying effect (along with the loss of episomal HPV DNA frequently observed upon progression) likely explains the reduced intra-sample sequence diversity observed in CIN3 and invasive lesions in this study. This observation is also consistent with the findings from a much larger-scale study in which HPV-16 genomes from 5570 samples representing productive (largely cervical), precancerous and invasive lesions were sequenced, revealing a remarkable degree of inter-host variation that was again highest in productive lesions. In this study, the authors observed that approximately $80 \%$ of individuals harboured unique (differing by at least two nucleotides from other samples) HPV-16 genomes, with the sequence context in which these variants occurred again implicating A3 activity in HPV evolution (Mirabello et al. 2017). Taken together then, A3 editing of HPV occurs at a frequency much lower than that observed for retroviruses such as HIV-1, rendering a role for deamination in HPV restriction highly unlikely. Rather, the low level of editing detected in these sequencing studies suggests an ongoing role for A3 activity in shaping HPV evolution by introducing variation otherwise lacking in a virus that is replicated with such high fidelity.

\section{Modulation of A3 gene expression by HPV}

Tight regulation of A3 expression and activity is presumably essential for limiting their potential mutagenic activity but as we have discussed, in addition to a possible restriction activity against HPV, there may be an evolutionary advantage to the virus from inducing at least a certain level of A3 expression (see Fig. 3 for a summary of pathways currently implicated in A3A and A3B transcriptional regulation and their modulation by HR-E6 and E7 proteins). Whether induction of A3 expression by HR-HPV types is a trait that the viruses have evolved to promote adaptation and immune evasion, a host response mechanism that has evolved to inhibit viral replication or a combination of the two, it may be an important cause of A3-mediated host genome mutagenesis and therefore of viral carcinogenesis. One likely candidate for host genome mutagenesis, the nuclear-localized A3B, is expressed at low basal levels in normal adult tissues, but it is often highly expressed in cancer biopsies, at least at the mRNA level (Jarmuz et al. 2002, Burns et al. 2013a) suggesting it may be playing an important ongoing role in mutagenesis at the time of diagnosis and potentially therefore, in driving therapeutic resistance. Indeed, high A3B mRNA levels in biopsy specimens are associated with poor prognosis in oestrogen receptor (ER)+ breast cancer (Sieuwerts et al. 2014, Periyasamy et al. 2015, Law et al. 2016). Unlike in breast and ovarian cancer, A3B mRNA levels are not correlated with A3 signature mutation burden in HPV-associated cancers (Roberts et al. 2013, Henderson et al. 2014, Ojesina et al. 2014), but A3B expression is consistently elevated in HPV-associated cancers in comparison to both normal tissue and to HPVindependent cancers arising at equivalent anatomic sites (Chakravarthy et al. 2016). These observations, together with the aforementioned studies demonstrating A3B upregulation by HR-HPV types (Vieira et al. 2014, Warren et al. 2015a), suggest an important role for A3B not only in HPV-associated cancer but also possibly in the viral life cycle. Here, we review several recent studies that have detailed various mechanisms by which HPV modulates expression of $\mathrm{A} 3 \mathrm{~B}$ and other $\mathrm{A} 3$ genes.

Mori and colleagues identified two E6-responsive regions in the A3B promoter: basal promoter activity in human keratinocytes can be activated by E6 at a distal region ( -200 to -51$)$, while a proximal region $(+1$ to +45 ) exerts inhibition of gene expression which can be relieved by E6, acting through the zinc finger protein ZNF384 through an as-yet unknown mechanism (Mori et al. 2015). Consistent with previous findings from the Harris lab (Burns et al. 2013a), Periyasamy et al. recently demonstrated an inverse relationship between TP53 status and A3B expression levels in both primary breast tumours and breast cancer cell lines (Periyasamy et al. 2017). As mentioned earlier, HR-HPVs have evolved a strategy by which to overcome p53-mediated cell cycle control. The E6 oncoprotein binds to a short LxxLL consensus sequence within the cellular ubiquitin ligase, E6AP, forming a heterodimer (Huibregtse et al. 1991, Martinez-Zapien et al. 2016). A trimeric complex is subsequently formed by the recruitment of p53, leading to ubiquitin-dependent p53 proteasomal degradation (Scheffner et al. 1993). Using a combination of RNA interference and pharmacological induction of p53 protein with Nutlin-3 in breast cancer cell lines, they elucidated a mechanism whereby p53 represses A3B expression via the action of its target gene, p21 WAF1/CIP1 (CDKN1A), in stabilizing the E2F4/DP1/p107/ p130-containing DREAM (DP1, RB-like, E2F4, and MuvB) transcriptional repressor complex (Fischer et al. 2014) at cell cycle genes homology region (CHR) elements in the A3B promoter. They also demonstrated that both the E6 
and E7 proteins from HPV16 can act independently to increase A3B expression in immortalized keratinocytes through this pathway; E6 via p53 degradation, with E7 likely acting through its effects on the p107 and p130 $\mathrm{pRb}$ family pocket proteins in the DREAM complex (Periyasamy et al. 2017), thus also offering a mechanistic basis for the E7-mediated A3B upregulation previously observed by Warren and colleagues (Warren et al. 2015a).

The A3B promoter also harbours target elements for the TEAD family of transcription factors (TEAD1-4 in mammals) (Mori et al. 2017). These evolutionarily conserved transcription factors, that recognize the consensus DNA sequence (AGGAATG) mediate expression of multiple genes involved in cell proliferation, epithelialmesenchymal transition and apoptosis evasion, acting in complexes with TAZ (transcriptional co-activator with PDZ binding motif) or YAP (Yes-associated protein), both of which are phosphorylated and inhibited by the Hippo tumour suppressor pathway (Jacquemin et al. 1996, Zhao et al. 2008, Zhang et al. 2009, Zhu et al. 2015). E6 induces TEAD1 and TEAD4 expression in keratinocytes and increases YAP protein levels by preventing it's degradation, although the TEAD-dependent induction of A3B appears to be YAP/TAZ-independent and may instead involve alternative coactivators (He et al. 2015, Mori et al. 2017).

E6 mediated p53 degradation therefore not only de-represses A3B transcription via the DREAM complex but also results in increased levels of TEAD expression, further activating the A3B promoter. Finally, it has been reported that replication stress induced by oncogenic pathway activation or by chemotherapy agents such as hydroxyurea or gemcitabine also causes ATR/CHK1dependent upregulation of A3B, at least in breast cancer cell lines (Kanu et al. 2016). High E6/E7 levels might similarly drive A3B upregulation via this as-yet undefined replication stress mechanism, thus together with the ZNF384-mediated effects and the additional activity of E7 in potentiating A3B expression, it appears that HPV could upregulate A3B via multiple mechanisms. Importantly, some of these mechanisms may act during the productive life cycle, while others may be restricted to precancerous/ cancerous cells in which HPV has integrated into the host genome, the life cycle has been aborted and only highlevel E6/E7 expression remains. It is also worth noting that in cells with wild-type TP53, A3B over-expression induces ATR/CHK1-dependent cell cycle arrest and apoptosis (Nikkilä et al. 2017). By removing p53 then, HPV not only activates A3B transcription but possibly also allows the A3B protein to accumulate to levels that would not otherwise be tolerated in normal cells.
Although the regulation of A3B by HPV has been the focus of much attention, it is important to consider the roles that other A3 genes may play, both in the response to HPV infection and potentially, in HPV-associated cancer. In their key paper reporting the first evidence for APOBEC editing of HPV in human cells, Vartanian and colleagues noted that HPV1a DNA co-transfected with $\mathrm{A} 3 \mathrm{~A}, \mathrm{~A} 3 \mathrm{C}$ and $\mathrm{A} 3 \mathrm{H}$ but not $\mathrm{A} 3 \mathrm{~B}$ displayed evidence of cytosine deamination (Vartanian et al. 2008), and while low-risk HPV genomes isolated from warts display evidence of A3 editing, several tested low-risk E6 variants did not upregulate A3B in cultured keratinocytes (Vieira et al. 2014).

Taken together with the findings of Warren and colleagues, that A3A but not A3B inhibits HPV infectivity, we should at least consider the possibility that the A3 response to HPV infection is entirely separate from any role in host mutagenesis during cancer development, with the former mediated by $\mathrm{A} 3 \mathrm{~A}$ and/or $\mathrm{A} 3 \mathrm{C}, \mathrm{A} 3 \mathrm{H}$ and the latter mediated by A3B. An alternative hypothesis is that although A3B is induced by HPV, it is not responsible for the mutations seen in either viral or host genomes. Consistent with this possibility is work from the Gordenin lab showing that, at least when expressed in yeast A3A and $\mathrm{A} 3 \mathrm{~B}$ generate subtly different mutation signatures, in which $\mathrm{A} 3 \mathrm{~A}$ preferentially targets YTCA sites (i.e. a pyrimidine at the -2 position) while A3B targets RTCA (i.e. a purine at the -2 position). Upon analysis of tumour exome data, they found much greater enrichment of the YTCA (A3A) signature across multiple tumour types including cervical cancer (Chan et al. 2015). The apparent preference of $\mathrm{A} 3 \mathrm{~A}$ for pyrimidine at -2 is also supported by in vitro studies using purified enzyme (Shi et al. 2017, Silvas et al. 2018). These observations suggest A3A, rather than A3B, may be the major source of somatic mutations to the host genome in HPV-associated cancer, although further functional investigation (e.g. analysis of A3 signature mutation accumulation in A3A or A3B knockout cells expressing HPV oncogenes) will be required to help solve this question.

\section{Additional cellular signalling pathways linked to $\mathrm{A} 3$ regulation}

The appearance of the A3 mutational signature in genomes of cancers with (presumably) no viral aetiology clearly implicates alternative mechanisms for A3 induction. In addition to the p53-dependent repression and ATR/CHK1dependent induction of $\mathrm{A3B}$ discussed above, several additional cellular pathways have been shown to induce 
A3 expression and it is worth considering how they may contribute to A3 activity against viral or host genomes in HPV-infected cells.

\section{Protein kinase $\mathrm{C}(\mathrm{PKC})$ signalling}

The twelve PKC isoforms regulate a plethora of biological processes and are characterized as conventional/classical (cPKC), novel (nPKC), or atypical (aPKC). Receptormediated activation of phospholipase $\mathrm{C}$ gamma (PLC) causes hydrolysis of the plasma membrane lipid, phosphatidylinositol 4,5-bisphosphate $\left(\mathrm{PIP}_{2}\right)$, into diacylglycerol (DAG) and inositol trisphosphate (IP3), with the latter stimulating release of intracellular $\mathrm{Ca}^{2+}$. Both DAG and $\mathrm{Ca}^{2+}$ are required for $\mathrm{CPKC}$ activation, while nPKC activation is DAG-dependent but $\mathrm{Ca}^{2+}$-independent (reviewed in Mellor \& Parker 1998, Newton 2003). By mimicking DAG, the phorbol ester, phorbol 12-myristate 13-acetate (PMA, a tumour promoter in animal models) potently activates both the cPKCs and nPKCs. Depending on the cell type examined, both A3A and A3B induction has been reported upon activation of PKC signalling: A3A was originally identified as Phorbolin-1, a protein enriched in psoriatic keratinocytes that could be induced by treatment of normal keratinocytes with PMA (Rasmussen \& Celis 1993, Madsen et al. 1999), while A3B but not A3A, is induced following PMA treatment of the mammary epithelial cell line, MCF10A (Leonard et al. 2015). Conversely, while a recent study conducted in normal oral keratinocytes (Siriwardena et al. 2018) and our own observations using NIKS in which we have epitope-tagged the endogenous $\mathrm{A} 3 \mathrm{~A}$ and $\mathrm{A} 3 \mathrm{~B}$ genes (Smith \& Fenton unpublished) confirm a strong, protein kinase $\mathrm{C}$ (PKC)dependent increase in A3A protein expression upon PMA treatment, $\mathrm{A} 3 \mathrm{~B}$ mRNA is induced to a far lesser extent in keratinocytes, with minimal or no detectable increase in A3B protein.

PKC isoforms perform important functions in keratinocyte proliferation and differentiation (Dlugosz \& Yuspa 1993, Denning et al. 1995, Papp et al. 2003, Yang et al. 2003, Seo et al. 2004) and in the context of HPV infection, PKC- $\alpha$ and PKC- $\delta$ are required for high-risk HPV31 genome amplification during the intermediate phase of viral replication, while expression of E5 from HPV16 in mouse fibroblasts causes PKC activation through activation of PLC $\gamma$ (Crusius et al. 1999, Bodily et al. 2006). Interestingly, both $\mathrm{A} 3 \mathrm{~A}$ and $\mathrm{A} 3 \mathrm{~B}$ were recently shown to be upregulated during $\mathrm{Ca}^{2+}$-stimulated differentiation of W12 cells (Wakae et al. 2018) and although the intracellular pathway mediating $\mathrm{Ca}^{2+}$-induced $\mathrm{A} 3 \mathrm{~A} / \mathrm{B}$ upregulation was not investigated in this study, it is well-established that increases in extracellular $\mathrm{Ca}^{2+}$ trigger activation of PKCs via PLC in keratinocytes (Jaken \& Yuspa 1988). Activation of PKC signalling during differentiation of HPV-infected keratinocytes is therefore a likely means by which at least A3A and possibly also A3B could become upregulated during productive HPV infections, potentially triggering viral genome editing alongside amplification.

\section{Viral nucleic acid sensing/interferon signalling}

Antiviral responses can be triggered through the sensing of foreign DNA in endosomes by a subset of Toll-like receptors (TLRs), or in the cytoplasm by the cyclic GMP-AMP synthase (cGAS)/stimulator of interferon gene (STING) pathway (Lebre et al. 2007, Suspène et al. 2017). Both pathways result in the induction of type-1 interferons (IFNs), which in turn induce a host of interferon-stimulated genes (ISGs, including several A3s) with a broad range of antiviral activities, and both are inhibited by HPV, suggesting a role in sensing the virus (Hasan et al. 2007, Albertini et al. 2018). Human keratinocytes express several TLRs, among which TLR9 is activated by DNA-containing unmethylated CpG motifs including a region from the HPV16 E6 gene (Hasan et al. 2007, 2013, Lebre et al. 2007). In addition to type 1 interferons it induces tumour necrosis factor (TNF $\alpha$ ), which has recently been shown to upregulate $\mathrm{A} 3 \mathrm{~A}$ in keratinocytes (Amcheslavsky et al. 2004, Siriwardena et al. 2018). The suppression of TLR9 by E7 provides further evidence of its importance in the innate immune responses to HPV (Hasan et al. 2007, 2013).

Both cGAS and the retinoic acid-inducible gene I (RIG-I, a sensor of viral RNA) have been implicated in keratinocyte responses to HPV infection, and RIG-I is required for induction of $\mathrm{A} 3 \mathrm{~A}$ expression by cytoplasmic DNA in the monocytic leukaemia cell line, THP-1 (Suspène et al. 2017, Albertini et al. 2018, Chiang et al. 2018). Until recently, it was thought that sensing of viral DNA was limited to the cytoplasm or endosome; however, sensors of nuclear viral DNA (IFI16, recently reported to restrict HPV18 replication Lo Cigno et al. 2015 and IFIX) have been described that also act together with cGAS to induce IFN responses (reviewed in Diner et al. 2015), thus providing another mechanism by which A3 activity could be induced in HPV-infected cells. Finally, HPV16 genome integration triggers a type I IFN response in keratinocytes, leading to episome clearance, loss of E2 expression and therefore upregulation of E6/E7 expression from the integrated virus (Pett et al. 2006). Whether viral 
integration is accompanied by IFN induction in vivo remains unknown but if so it could generate a burst of A3 expression in neoplastic cells consistent with the proposed pulsatile nature of the APOBEC mutational process (Helleday et al. 2014).

Downstream of viral nucleic acid sensing and PKC pathways lie NFKB transcriptional complexes known to participate in regulating A3B expression (Leonard et al. 2015, Maruyama et al. 2016). NFKB complexes are also directly activated by HR-E6; they become progressively activated during cervical cancer development (Nees et al. 2001, James et al. 2006, Da Costa et al. 2016, Tilborghs et al. 2017) and therefore likely contribute to the high A3B expression levels seen in these and other HPV-associated tumours. Finally, while little is yet known about how the $\mathrm{A} 3$ proteins are regulated, $\mathrm{A} 3 \mathrm{~A}$ and $\mathrm{A} 3 \mathrm{C}$ have both been reported to bind the pseudokinase, TRIB3. TRIB3 is localized to the nucleus and appears to target nuclear A3A for degradation, thus inhibiting deamination of genomic DNA upon transfection of A3A into Hela cells (Aynaud et al. 2012). Knockdown of TRIB3 expression also increased A3A levels in NIKS but without an apparent stabilization of the protein (Westrich et al. 2018), while in a third study, Land and colleagues saw no effect of TRIB3 on A3A-GFP levels in HEK293T cells but did not report whether the A3A-TRIB3 interaction (initially observed in a yeast-2-hybrid screen) still occurred (Land et al. 2013). The fusion of GFP to A3A could possibly explain the absence of TRIB3 regulation in the latter study, but further work is required to determine the significance of the A3ATRIB3 interaction.

\section{Current questions}

We have seen that multiple A3s can be induced in HPVinfected cells and that circumstantial evidence supports a role for either or both $\mathrm{A} 3 \mathrm{~A}$ and $\mathrm{A} 3 \mathrm{~B}$ in generating mutations in host and viral genomes. Other A3s (A3C, $\mathrm{A} 3 \mathrm{G}$ and $\mathrm{A} 3 \mathrm{H}$ ) all remain potential candidates, at least for viral genome editing. One outstanding question is whether viral and host genome editing are linked events, mediated by the same A3 at the same time. In this model, HPV induces A3 activity as discussed, possibly to generate variation in viral progeny, suppress retroelement replication-induced interferon responses or to mediate transcriptional functions allowing suppression of TLR9 expression or induction of DNA replication. Due to other activities of the virus, however, such as the induction of replication stress, A3 activity against the host genome can also occur and in rare circumstances, this results in mutations in cancer-causing genes such as PIK3CA. Cells in which these mutations occur will gain a selective survival advantage but may remain held in-check by the host immune system for many years and/or lack additional genetic or epigenetic changes required to form an invasive carcinoma. In this scenario, A3 activity may contribute to tumour development even from the earliest stages of an HPV infection. This scenario is represented in Fig. 4 as 'Early, transient' or 'Early, sustained' temporal models of A3 activity, depending on whether tumour subclones in which A3 mutagenesis has occurred early sustain high A3 activity or whether this is subsequently selected against due to increased chance of deleterious mutations and/or generation of neoantigens and therefore immune-mediated elimination ('cancer immuoediting' (Schreiber et al. 2011)). It is noteworthy that HPV genomes are physically tethered to fragile sites in the host genome via the chromatin modifier, BRD4 (Jang et al. 2014); thus, their replication (and likely A3 editing) occurs in very close proximity to host DNA, potentially increasing the danger of off-target A3 activity, particularly during the stable maintenance phase of viral replication which unlike amplification occurs concurrently with cellular genome replication in S-phase (Sakakibara et al. 2013, Reinson et al. 2015). Alternatively, the initial A3 response to viral infection may result in editing of HPV but not host DNA, with aberrant activity against the host genome coming much later, for example, induced by IFN signalling associated with episome clearance or subsequent upregulation of E6/E7 from integrants due to loss of E2 expression. Either way, the genomic instability caused by high-level E7 expression, together with the removal of p53 by E6 and chronic activation of NF- $\mathrm{kB}$ could all fuel A3 mutagenesis throughout tumour development, not necessarily mediated by the same A3(s) responsible for the viral editing seen in benign lesions. This scenario is represented in Fig. 4 as 'Late, transient' or 'Late sustained' A3 activity, again depending on whether A3 mutagenesis is ongoing at the time of diagnosis and subsequently during treatment (see below). Given the mutational and gene expression data currently available, it is difficult to say which of these models is the more likely, not least because almost all these data come from resected primary tumour samples (Fig. 4). At least in the case of cervical cancer, it is possible to study precancerous lesions, affording a rare opportunity to address some of these questions; a targeted NGS study in which a panel of 48 cancer-associated genes including PIK3CA were sequenced in 35 cervical cancers and 23 CIN2/3 lesions found only the PIK3CA exon 9 (A3-mediated) mutations 
HR:HPV infection

CIN3
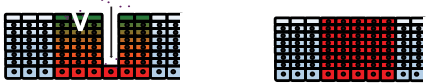

Invasive carcinoma

Metastatic carcinoma

Recurrent disease

(1)

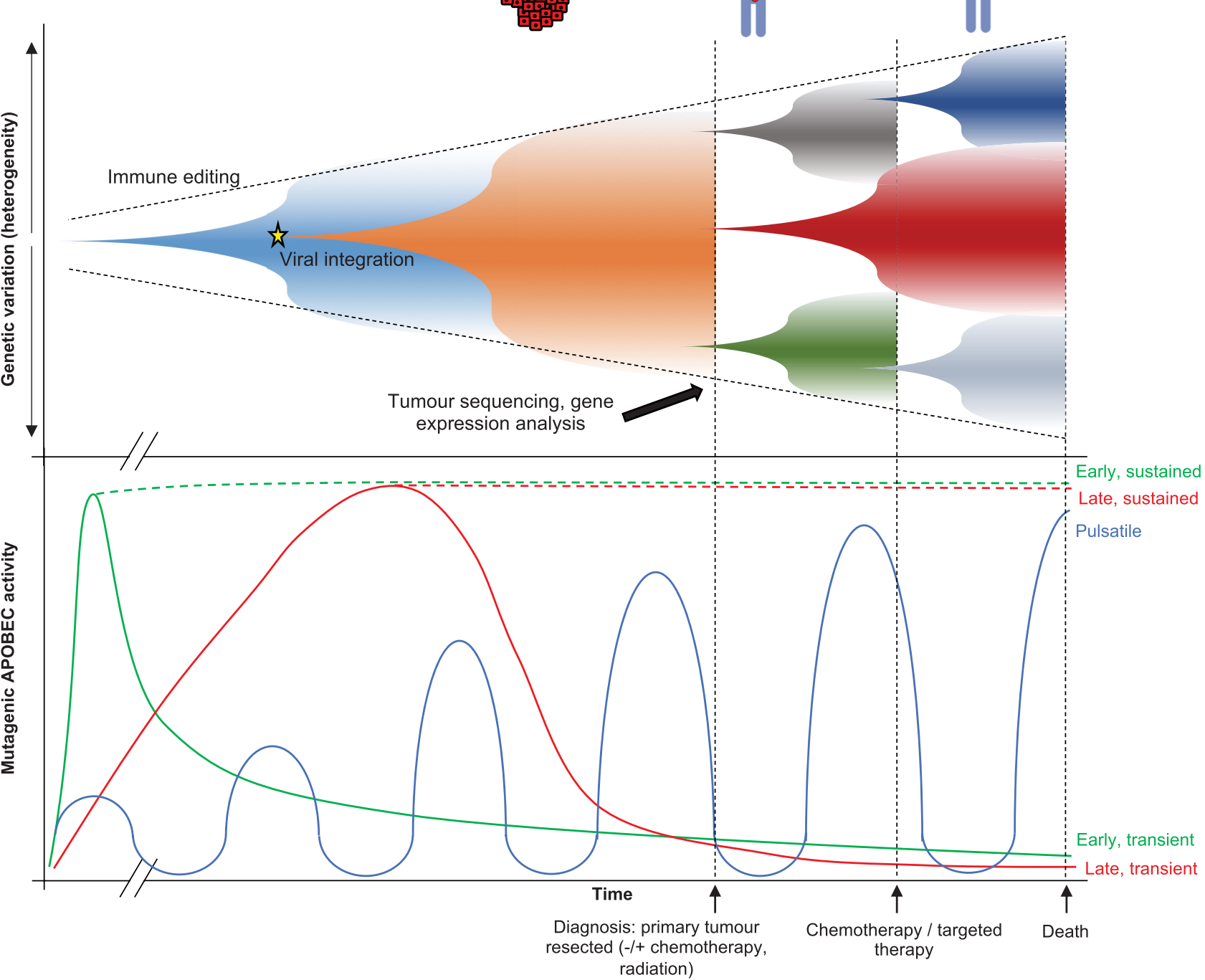

Figure 4

A clonal selection model for HPV-associated tumour development and progression, with alternative models for temporal involvement of A3 activity. Top panel: following persistent HPV infection, somatic alterations begin to accumulate in the host cell genome, resulting in clonal expansion and the appearance of multiple subclones (increased genetic variation, $y$-axis). Typically, cells in which viral integration occurs at particular site(s) in the host cell genome will outgrow surrounding neoplastic clones, resulting in an invasive carcinoma that is diagnosed and removed. The vast majority of information regarding somatic mutations, mutational signatures and A3 gene expression currently comes from samples taken at this point; thus, it is not clear when A3 mutagenesis occurs during tumour development, whether it is ongoing at the time of diagnosis and treatment and how it contributes to adaptation to continual selection pressures or selective sweeps such as those shown in black dashed lines (immunoediting or radiotherapy/chemotherapy respectively). Bottom panel: alternative models for the temporal pattern of A3 activity (y-axis) against the host genome during HPV-associated tumour development and progression (see main text for details). Note that the y-axis represents 'mutagenic A3 activity' and not the expression of any one A3 enzyme. It is possible that different A3s could be active at different stages of tumour development.

were detectable in the CIN2/3 lesions, with the rest exclusive to invasive carcinoma. PIK3CA exon 9 was then Sanger-sequenced in a further 35 cervical carcinomas, 209 CIN3, 144 CIN2, 154 CIN1 and 105 normal samples, with mutations detected in $37 \%$ of carcinomas but only $2.4 \%$ of CIN3 lesions and none in earlier lesions or normal cervix, leading the authors to conclude this is a late event in cervical carcinogenesis (Verlaat et al. 2015). It is important to note, however, that Sanger sequencing would not have permitted the detection of PIK3CA mutations in minor subclones that could be present from a much earlier stage in carcinogenesis; thus, 
ultra-deep sequencing of CIN lesions will be required to fully address this question.

Analysis of allele frequency (a measure of the clonality or proportion of tumour cells in which a mutation is found and therefore a proxy for the time at which it occurred) for cancer driver mutations seen in TCGA WES data suggests that A3 signature mutations become increasingly enriched in later stages of tumour development in several tumour types. A3 mutations in lung adenocarcinoma are largely subclonal (i.e. those occurring later), often 'taking over' from the tobacco-associated signature, which generates clonal driver mutations (i.e. initiating or early events) in smokers, consistent with its role in lung carcinogenesis (de Bruin et al. 2014, McGranahan et al. 2015). In bladder cancer, A3 signature mutations appear in pre-invasive tumours but continue to accumulate through progression, becoming increasingly enriched in muscleinvasive disease, as confirmed by sequencing of matched metachronous samples (Nordentoft et al. 2014, Lamy et al. 2016). Interestingly, in bladder cancer, it appears that one of the two A3 mutation signatures defined by Alexandrov and colleagues (signature 13) is enriched early, while the other (signature 2) becomes enriched in subclones (Alexandrov et al. 2013a, McGranahan et al. 2015). The reason for this is unclear but may reflect the differences in DNA replication across deaminated sites in early versus late tumours. In breast cancer, there is evidence that A3 signature mutations begin to accumulate prior to copy number changes and that A3-generated mutation clusters ('kataegis') appear at several distinct stages during the development of a single tumour, again implying pulses of A3 activity from an early point, represented in Fig. 4 as a 'Pulsatile' model for A3 mutagenesis (Nik-Zainal et al. 2012a,b, Helleday et al. 2014).

Maybe more important than the question of when A3 activity against the host genome first appears, is whether it is ongoing at the time of diagnosis (as represented by the 'Early, sustained', 'Late, sustained' and 'Pulsatile' models for A3 mutagenesis set out in Fig. 4). Experiments in cultured cells suggest that acquired resistance to cancer therapy can occur both by selection of rare, pre-existing drug-resistant subclones and de novo mutations in 'drugtolerant' cells (Hata et al. 2016, Ramirez et al. 2016), and evidence that A3 activity continues to generate mutations during treatment is accumulating, both from sequencing of metastatic bladder cancer, post-gemcitabine/ cisplatin-based chemotherapy (Faltas et al. 2016) and from experimental models, in which chemotherapy drugs including gemcitabine have been shown to induce $\mathrm{A} 3 \mathrm{~B}$ expression and deaminase activity via
ATR/CHK1 signalling (Kanu etal. 2016). These observations suggest A3 activity could contribute to the evolution of therapeutic resistance, a possibility that is supported by a recent study in which suppression of A3B expression by inducible RNA interference delayed the acquisition of tamoxifen resistance in a xenografted breast cancer cell line (Law et al. 2016). Increased A3B expression is also associated with shorter overall survival and progressionfree survival in patients receiving tamoxifen treatment in ER+ breast cancer (Sieuwerts et al. 2014, Law et al. 2016). It appears then that there could be therapeutic benefit to be gained through inhibiting A3B and/or other A3 enzymes as an adjuvant to chemotherapy; a notion underlying $\mathrm{A} 3$ drug discovery efforts currently underway in academia and industry (Olson et al. 2018, Venkatesan et al. 2018). In addition to suppressing de novo mutagenesis and therefore the emergence of drug-resistant subclones, an inhibitor of A3B could also have anticancer effects by interfering with its activity as an ER transcriptional co-activator in breast but possibly also in other oestrogen-responsive tissues including the cervix as discussed earlier and ovarian cancer - another malignancy in which A3B activity has been implicated (Leonard et al. 2013).

One important consideration for developing A3 inhibitors as cancer therapies is whether a selective inhibitor would be preferable to a pan-A3 inhibitor and if so, which would be the best A3 to target. A rationale for selectively targeting A3B comes from the fact that it is a non-essential gene in humans, as evidenced by the existence of a deletion polymorphism (A3A_B) in which the A3A 3'-untranslated region (UTR) and entire A3B open-reading frame (ORF) are absent and the A3A ORF is fused to the A3B 3' UTR (Fig. 2). This polymorphism displays a remarkable stratification across the global population, with a prevalence of $1 \%$ in Africa rising to approximately 40\% in South East Asia and South America and approaching fixation in Oceania (Kidd et al. 2007). Somewhat surprisingly given the demonstrated mutagenic and pro-growth functions of A3B in breast cancer cell lines, this deletion allele is associated with an approximately two-fold increased breast and ovarian cancer risk in Asian populations and in certain European cohorts (Long et al. 2013, Xuan et al. 2013, Qi et al. 2014, Middlebrooks et al. 2016, Wen et al. 2016). A recent Scandinavian study meanwhile found an increased lung cancer risk in A3A_B carriers aged younger than 50 years and a similar agerelated trend for prostate cancer risk but no association with breast cancer risk, a result consistent with a further study conducted in Sweden (Göhler et al. 2016, Gansmo et al. 2018). The reason for the increased cancer risk 
associated with A3A_B remains unclear, but it was shown that breast cancers from women carrying at least one copy of the deletion allele harbour an increased burden of A3-related mutations, suggesting another A3 enzyme is hyper-activated in these tumours (Nik-Zainal et al. 2014). A hybrid A3A transcript encoded by a recombinant cDNA based on the A3A_B allele accumulates to levels approximately two-fold higher than those of A3A bearing its own 3'-UTR in transient transfection experiments and in a Taiwanese oral squamous cell carcinoma (OSCC) cohort, A3A was upregulated at both mRNA and protein levels and the A3 mutation signature was enriched in the $50 \%$ of patients carrying the A3A_B allele (Caval et al. 2014; Chen et al. 2017). Another study however proposed that mutations in A3A_B tumours are generated by a specific variant of the polymorphic $\mathrm{A} 3 \mathrm{H}$ gene. This variant $(\mathrm{A} 3 \mathrm{H}$ haplotype I) encodes a less stable but nuclear-localized protein that does not display linkage disequilibrium with A3A_B but those A3A_B homozygous breast tumours with the highest A3 signature mutation loads in TCGA cohort were found to be hetero- or homozygous for A3H-I (Starrett et al. 2016). An A3B-selective inhibitor would therefore not be expected to display on-target toxicity, although it would clearly be ineffective in A3A_B patients. In the Taiwanese OSCC study, A3A expression was associated with longer disease-specific, disease-free and overall survival specifically in those patients heteroor homozygous for A3A_B, again supporting a key role for A3A in these tumours (Chen et al. 2017). The authors of this study found that A3A expression was reduced in tumours of higher stage, but A3A expression was nevertheless significantly associated with both overall and disease-specific survival in a multivariate analysis including clinicopathological variables such as age, tumour stage, grade and evidence of perineural or bone invasion, in A3A_B carriers. The magnitude of this effect was marked, with a disease-specific survival hazard ratio of 0.444 for 'A3A-high' tumours vs 'A3A-low' tumours. It is possible that the improved survival in this group could be linked to increased neoantigen loads and therefore an enhanced adaptive immune response, as recently posited for lung cancer, in which tumours with higher A3B levels displayed greater immune infiltration and more durable responses to immune checkpoint blockade (Wang et al. 2018) and for bladder cancer, in which a higher A3 signature mutation load was associated with improved prognosis (Middlebrooks et al. 2016). It is also possible that the A3A expression detected in the Taiwanese OSCC cohort emanated from infiltrating leukocytes rather than the tumour cells, thus serving as a marker of immune infiltration. In this regard, it is interesting that the A3A_B allele has previously been linked to increased immune infiltration in breast cancer (Cescon et al. 2015, Wen et al. 2016). More studies on the expression and activity of the A3 enzymes in A3A_B cells and tumours will be required to resolve these questions and more epidemiological studies are needed to investigate potential associations between A3A_B and risk of other cancers, including HPV-associated cancer. Given that A3A and A3B are induced by HR-HPV, HPV-associated cancers display such strong enrichment for the A3 mutational signature, and A3 activity appears to generate within-host sequence variation in the viral genome, we might expect A3A_B to confer an altered risk, either of persistent HPV infection and/or carcinogenesis, and possibly even prognosis.

\section{Conclusions}

One or more of the A3 genes play important roles in the development of HPV-associated cancers, by generating somatic mutations in the host genome but potentially also via their activity against the virus. Our current understanding of A3-mediated mutagenesis in tumour cells stems in large part from analysis of cancer sequencing data, supported by studies in which A3 enzymes have been expressed either in human or yeast cells. The prospects of utilising A3s as predictive biomarkers for cancer immunotherapy or targets for cancer treatment are tantalising but much remains to be learned regarding which A3s are the most important players in different cancers and how they become deregulated. To address such questions, we will need to develop and utilize models in which we can study individual A3 genes in relevant models of HPV infection and carcinogenesis. The relative ease of conducting loss-of-function studies enabled by CRISPR-Cas9 technology (Shalem et al. 2015) should facilitate progress in this regard, as will the chemical probes that we hope will soon emerge from A3 inhibitor programmes (Olson et al. 2018). Studying A3 function in animal models remains a challenge but approaches such as the expression of A3 transgenes in a mA3-null background provide useful proof-of-concept and good mouse models of E6/E7-driven carcinogenesis are available (Riley et al. 2003, Strati et al. 2006, Stavrou et al. 2014). In conclusion, the exploration of A3 involvement in cancer is still a new field; much remains unknown and we anticipate many exciting developments in the coming years. 


\section{Declaration of interest}

The authors declare that there is no conflict of interest that could be perceived as prejudicing the impartiality of this review.

\section{Funding}

Work on APOBEC3 genes and HPV in the T R F lab is supported by funding from Cancer Research UK (A25825) and Rosetrees Trust (M229-CD1).

\section{Acknowledgements}

The authors thank Nnenna Kanu, Subramanian Venkatesan and John Doorbar for critical reading and suggestions and apologise to those authors whose work we have not been able to reference due to space restrictions.

\section{References}

Ahasan MM, Wakae K, Wang Z, Kitamura K, Liu G, Koura M, Imayasu M, Sakamoto N, Hanaoka K, Nakamura M, et al. 2015 APOBEC3A and 3C decrease human papillomavirus 16 pseudovirion infectivity. Biochemical and Biophysical Research Communications 457 295-299. (https://doi.org/10.1016/j.bbrc.2014.12.103)

Albertini S, Lo Cigno I, Calati F, De Andrea M, Borgogna C, Dell'Oste V, Landolfo S \& Gariglio M 2018 HPV18 persistence impairs basal and DNA ligand-mediated IFN- $\beta$ and IFN- $\lambda 1$ production through transcriptional repression of multiple downstream effectors of pattern recognition receptor signaling. Journal of Immunology 200 2076-2089. (https://doi.org/10.4049/jimmunol.1701536)

Alexandrov LB, Nik-Zainal S, Wedge DC, Aparicio SAJR, Behjati S, Biankin AV, Bignell GR, Bolli N, Borg A, Børresen-Dale A-L, et al. $2013 a$ Signatures of mutational processes in human cancer. Nature 500 415-421. (https://doi.org/10.1038/nature12477)

Alexandrov LB, Nik-Zainal S, Wedge DC, Campbell PJ \& Stratton MR $2013 b$ Deciphering signatures of mutational processes operative in human cancer. Cell Reports 3 246-259. (https://doi.org/10.1016/j. celrep.2012.12.008)

Amcheslavsky A, Zou W \& Bar-Shavit Z 2004 Toll-like receptor 9 regulates tumor necrosis factor-alpha expression by different mechanisms. Implications for osteoclastogenesis. Journal of Biological Chemistry 279 54039-54045. (https://doi.org/10.1074/jbc. M409138200)

Aynaud M-M, Suspène R, Vidalain P-O, Mussil B, Guétard D, Tangy F, Wain-Hobson S \& Vartanian J-P 2012 Human Tribbles 3 protects nuclear DNA from cytidine deamination by APOBEC3A. Journal of Biological Chemistry 287 39182-39192. (https://doi.org/10.1074/jbc. M112.372722)

Bodily J \& Laimins LA 2011 Persistence of human papillomavirus infection: keys to malignant progression. Trends in Microbiology 19 33-39. (https://doi.org/10.1016/j.tim.2010.10.002)

Bodily JM, Alam S \& Meyers C 2006 Regulation of human papillomavirus type 31 late promoter activation and genome amplification by protein kinase C. Virology 348 328-340. (https:// doi.org/10.1016/j.virol.2006.01.036)

Boshart M, Gissmann L, Ikenberg H, Kleinheinz A, Scheurlen W \& zur Hausen H 1984 A new type of papillomavirus DNA, its presence in genital cancer biopsies and in cell lines derived from cervical cancer. EMBO Journal 3 1151-1157. (https://doi. org/10.1002/j.1460-2075.1984.tb01944.x)

Brake T \& Lambert PF 2005 Estrogen contributes to the onset, persistence, and malignant progression of cervical cancer in a human papillomavirus-transgenic mouse model. PNAS 102 2490-2495. (https://doi.org/10.1073/pnas.0409883102)
Burns MB, Lackey L, Carpenter MA, Rathore A, Land AM, Leonard B, Refsland EW, Kotandeniya D, Tretyakova N, Nikas JB, et al. 2013a APOBEC3B is an enzymatic source of mutation in breast cancer. Nature 494 366-370. (https://doi.org/10.1038/nature11881)

Burns MB, Temiz NA \& Harris RS 2013b Evidence for APOBEC3B mutagenesis in multiple human cancers. Nature Genetics 45 977-983. (https://doi.org/10.1038/ng.2701)

Caval V, Suspène R, Shapira M, Vartanian JP \& Wain-Hobson S 2014 A prevalent cancer susceptibility APOBEC3A hybrid allele bearing APOBEC3B 3'UTR enhances chromosomal DNA damage. Nature Communications 5 5129. (https://doi.org/10.1038/ncomms6129)

Cescon DW, Haibe-Kains B \& Mak TW 2015 APOBEC3B expression in breast cancer reflects cellular proliferation, while a deletion polymorphism is associated with immune activation. PNAS 112 2841-2846. (https://doi.org/10.1073/pnas.1424869112)

Chakravarthy A, Henderson S, Thirdborough SM, Ottensmeier CH, Su X, Lechner M, Feber A, Thomas GJ \& Fenton TR 2016 Human papillomavirus drives tumor development throughout the head and neck: improved prognosis is associated with an immune response largely restricted to the oropharynx. Journal of Clinical Oncology 34 4132-4141. (https://doi.org/10.1200/JCO.2016.68.2955)

Chan K, Roberts SA, Klimczak LJ, Sterling JF, Saini N, Malc EP, Kim J, Kwiatkowski DJ, Fargo DC, Mieczkowski PA, et al. 2015 An APOBEC3A hypermutation signature is distinguishable from the signature of background mutagenesis by APOBEC3B in human cancers. Nature Genetics 47 1067-1072. (https://doi.org/10.1038/ ng.3378)

Chen H, Lilley CE, Yu Q, Lee DV, Chou J, Narvaiza I, Landau NR \& Weitzman MD 2006 APOBEC3A is a potent inhibitor of adenoassociated virus and retrotransposons. Current Biology 16 480-485. (https://doi.org/10.1016/j.cub.2006.01.031)

Chen TW, Lee CC, Liu H, Wu CS, Pickering CR, Huang PJ, Wang J, Chang IY-F, Yeh YM, Chen CD, et al. 2017 APOBEC3A is an oral cancer prognostic biomarker in Taiwanese carriers of an APOBEC deletion polymorphism. Nature Communications 8 465. (https://doi. org/10.1038/s41467-017-00493-9)

Chiang C, Pauli EK, Biryukov J, Feister KF, Meng M, White EA, Münger K, Howley PM, Meyers C \& Gack MU 2018 The human papillomavirus E6 oncoprotein targets USP15 and TRIM25 to suppress RIG-I-mediated innate immune signaling. Journal of Virology 92 e01737-17. (https://doi.org/10.1128/JVI.01737-17)

Chiu YL \& Greene WC 2008 The APOBEC3 cytidine deaminases: an innate defensive network opposing exogenous retroviruses and endogenous retroelements. Annual Review of Immunology 26317 353. (https://doi.org/10.1146/annurev. immunol.26.021607.090350)

Conticello SG 2008 The AID/APOBEC family of nucleic acid mutators. Genome Biology 9 229. (https://doi.org/10.1186/gb-2008-9-6-229)

Conticello SG, Thomas CJF, Petersen-Mahrt SK \& Neuberger MS 2005 Evolution of the AID/APOBEC family of polynucleotide (deoxy) cytidine deaminases. Molecular Biology and Evolution 22 367-377. (https://doi.org/10.1093/molbev/msi026)

Crusius K, Kaszkin M, Kinzel V \& Alonso A 1999 The human papillomavirus type 16 E5 protein modulates phospholipase C- $\gamma-1$ activity and phosphatidyl inositol turnover in mouse fibroblasts. Oncogene 18 6714-6718. (https://doi.org/10.1038/sj.onc.1203075)

Da Costa RMG, Bastos MMSM, Medeiros R \& Oliveira PA 2016 The NFкB signaling pathway in papillomavirus-induced lesions: friend or foe? Anticancer Research 36 2073-2083.

de Bruin EC, McGranahan N, Mitter R, Salm M, Wedge DC, Yates L, Jamal-Hanjani M, Shafi S, Murugaesu N, Rowan AJ, et al. 2014 Spatial and temporal diversity in genomic instability processes defines lung cancer evolution. Science 346 251-256. (https://doi. org/10.1126/science.1253462)

de Martel C, Plummer M, Vignat J \& Franceschi S 2017 Worldwide burden of cancer attributable to HPV by site, country and HPV type. 
International Journal of Cancer 141 664-670. (https://doi.org/10.1002/ ijc.30716)

Della Torre G, Pilotti S, De Palo G \& Rilke F 1978 Viral particles in cervical condylomatous lesions. Tumori 64 549-553. (https://doi. org/10.1177/030089167806400513)

Denning MF, Kazanietz MG, Blumberg PM \& Yuspa SH 1995 Cholesterol sulfate activates multiple protein kinase $\mathrm{C}$ isoenzymes and induces granular cell differentiation in cultured murine keratinocytes. Cell Growth and Differentiation-Publication American Association for Cancer Research 6 1619-1626.

Diner BA, Lum KK \& Cristea IM 2015 The emerging role of nuclear viral DNA sensors. Journal of Biological Chemistry $29026412-26421$. (https://doi.org/10.1074/jbc.R115.652289)

Dlugosz AA \& Yuspa SH 1993 Coordinate changes in gene expression which mark the spinous to granular cell transition in epidermis are regulated by protein kinase C. Journal of Cell Biology 120 217-225. (https://doi.org/10.1083/jcb.120.1.217)

Doorbar J, Quint W, Banks L, Bravo IG, Stoler M, Broker TR \& Stanley MA 2012 The biology and life-cycle of human papillomaviruses. Vaccine 30 F55-F70. (https://doi.org/10.1016/j. vaccine.2012.06.083)

Doorbar J, Egawa N, Griffin H, Kranjec C \& Murakami I 2015 Human papillomavirus molecular biology and disease association. Reviews in Medical Virology 25 (Supplement 1) 2-23. (https://doi.org/10.1002/ rmv.1822)

Dürst M, Gissmann L, Ikenberg H \& Zur Hausen H 1983 A papillomavirus DNA from a cervical carcinoma and its prevalence in cancer biopsy samples from different geographic regions. PNAS $\mathbf{8 0}$ 3812-3815. (https://doi.org/10.1073/pnas.80.12.3812)

Faltas BM, Prandi D, Tagawa ST, Molina AM, Nanus DM, Sternberg C, Rosenberg J, Mosquera JM, Robinson B, Elemento O, et al. 2016 Clonal evolution of chemotherapy-resistant urothelial carcinoma. Nature Genetics 48 1490-1499. (https://doi.org/10.1038/ng.3692)

Feber A, Worth DC, Chakravarthy A, de Winter P, Shah K, Arya M, Saqib M, Nigam R, Malone PR, Tan WS, et al. 2016 CSN1 somatic mutations in penile squamous cell carcinoma. Cancer Research $\mathbf{7 6}$ 4720-4727. (https://doi.org/10.1158/0008-5472.CAN-15-3134)

Fischer M, Steiner L \& Engeland K 2014 The transcription factor p53: not a repressor, solely an activator. Cell Cycle 13 3037-3058. (https:// doi.org/10.4161/15384101.2014.949083)

Forbes SA, Beare D, Boutselakis H, Bamford S, Bindal N, Tate J, Cole CG, Ward S, Dawson E, Ponting L, et al. 2017 COSMIC: somatic cancer genetics at high-resolution. Nucleic Acids Research 45 D777-D783. (https://doi.org/10.1093/nar/gkw1121)

Gansmo LB, Romundstad P, Hveem K, Vatten L, Nik-Zainal S, Lønning PE \& Knappskog S 2018 APOBEC3A/B deletion polymorphism and cancer risk. Carcinogenesis 39 118-124. (https:// doi.org/10.1093/carcin/bgx131)

Gillison ML, Akagi K, Xiao W, Jiang B, Pickard RKL, Li J, Swanson BJ, Agrawal AD, Zucker M, Stache-Crain B, et al. 2019 Human papillomavirus and the landscape of secondary genetic alterations in oral cancers. Genome Research 29 1-17. (https://doi.org/10.1101/ gr.241141.118)

Göhler S, Da Silva Filho MI, Johansson R, Enquist-Olsson K, Henriksson R, Hemminki K, Lenner P \& Försti A 2016 Impact of functional germline variants and a deletion polymorphism in APOBEC3A and APOBEC3B on breast cancer risk and survival in a Swedish study population. Journal of Cancer Research and Clinical Oncology 142 273-276. (https://doi.org/10.1007/s00432-015-2038-7)

Green AM, Landry S, Budagyan K, Avgousti DC, Shalhout S, Bhagwat AS \& Weitzman MD 2016 APOBEC3A damages the cellular genome during DNA replication. Cell Cycle 15 998-1008. (https://doi.org/10. 1080/15384101.2016.1152426)

Haradhvala NJ, Polak P, Stojanov P, Covington KR, Shinbrot E, Hess JM, Rheinbay E, Kim J, Maruvka YE, Braunstein LZ, et al. 2016 Mutational strand asymmetries in cancer genomes reveal mechanisms of DNA damage and repair. Cell 164 538-549. (https:// doi.org/10.1016/j.cell.2015.12.050)

Harris RS \& Dudley JP 2015 APOBECs and virus restriction. Virology 479-480 131-145. (https://doi.org/10.1016/j.virol.2015.03.012)

Harris RS, Petersen-Mahrt SK \& Neuberger MS 2002 RNA editing enzyme APOBEC1 and some of its homologs can act as DNA mutators. Molecular Cell 10 1247-1253. (https://doi.org/10.1016/S10972765(02)00742-6)

Harris RS, Bishop KN, Sheehy AM, Craig HM, Petersen-Mahrt SK, Watt IN, Neuberger MS \& Malim MH 2003 DNA deamination mediates innate immunity to retroviral infection. Cell 113 803-809. (https://doi.org/10.1016/S0092-8674(03)00423-9)

Hasan UA, Bates E, Takeshita F, Biliato A, Accardi R, Bouvard V, Mansour M, Vincent I, Gissmann L, Iftner T, et al. 2007 TLR9 expression and function is abolished by the cervical cancerassociated human papillomavirus type 16. Journal of Immunology $\mathbf{1 7 8}$ 3186-3197. (https://doi.org/10.4049/jimmunol.178.5.3186)

Hasan UA, Zannetti C, Parroche P, Goutagny N, Malfroy M, Roblot G, Carreira C, Hussain I, Müller M, Taylor-Papadimitriou J, et al. 2013 The human papillomavirus type $16 \mathrm{E} 7$ oncoprotein induces a transcriptional repressor complex on the Toll-like receptor 9 promoter. Journal of Experimental Medicine 210 1369-1387. (https:// doi.org/10.1084/jem.20122394)

Hata AN, Niederst MJ, Archibald HL, Gomez-Caraballo M, Siddiqui FM, Mulvey HE, Maruvka YE, Ji F, Bhang HE, Krishnamurthy Radhakrishna V, et al. 2016 Tumor cells can follow distinct evolutionary paths to become resistant to epidermal growth factor receptor inhibition. Nature Medicine 22 262-269. (https://doi. org/10.1038/nm.4040)

He C, Mao D, Hua G, Lv X, Chen X, Angeletti PC, Dong J, Remmenga SW, Rodabaugh KJ, Zhou J, et al. 2015 The Hippo/YAP pathway interacts with EGFR signaling and HPV oncoproteins to regulate cervical cancer progression. EMBO Molecular Medicine 7 1426-1449. (https://doi.org/10.15252/emmm.201404976)

Helleday T, Eshtad S \& Nik-Zainal S 2014 Mechanisms underlying mutational signatures in human cancers. Nature Reviews Genetics 15 585-598. (https://doi.org/10.1038/nrg3729)

Henderson S, Chakravarthy A, Su X, Boshoff C \& Fenton TR 2014 APOBEC-mediated cytosine deamination links PIK3CA helical domain mutations to human papillomavirus-driven tumor development. Cell Reports 7 1833-1841. (https://doi.org/10.1016/j. celrep.2014.05.012)

Hills E \& Laverty CR 1979 Electron microscopic detection of papilloma virus particles in selected koilocytotic cells in a routine cervical smear. Acta Cytologica 23 53-56.

Hirose Y, Onuki M, Tenjimbayashi Y, Mori S, Ishii Y, Takeuchi T, Tasaka N, Satoh T, Morisada T, Iwata T, et al. 2018 Within-host variations of human papillomavirus reveal APOBEC signature mutagenesis in the viral genome. Journal of Virology 92 e00017-18. (https://doi.org/10.1128/JVI.00017-18)

Holmes RK, Malim MH \& Bishop KN 2007 APOBEC-mediated viral restriction: not simply editing? Trends in Biochemical Sciences $\mathbf{3 2}$ 118-128. (https://doi.org/10.1016/j.tibs.2007.01.004)

Hoopes JI, Cortez LM, Mertz TM, Malc EP, Mieczkowski PA \& Roberts SA 2016 APOBEC3A and APOBEC3B preferentially deaminate the lagging strand template during DNA replication. Cell Reports $\mathbf{1 4}$ 1273-1282. (https://doi.org/10.1016/j.celrep.2016.01.021)

Huibregtse JM, Scheffner M \& Howley PM 1991 A cellular protein mediates association of p53 with the E6 oncoprotein of human papillomavirus types 16 or 18. EMBO Journal 10 4129-4135. (https:// doi.org/10.1002/j.1460-2075.1991.tb04990.x)

Jacquemin P, Hwang JJ, Martial JA, Dollé P \& Davidson I 1996 A novel family of developmentally regulated mammalian transcription factors containing the TEA/ATTS DNA binding domain. Journal of Biological Chemistry 271 21775-21785. (https://doi.org/10.1074/ jbc.271.36.21775) 
Jaken S \& Yuspa SH 1988 Early signals for keratinocyte differentiation: role of $\mathrm{Ca}^{2+}$-mediated inositol lipid metabolism in normal and neoplastic epidermal cells. Carcinogenesis 9 1033-1038. (https://doi. org/10.1093/carcin/9.6.1033)

James MA, Lee JH \& Klingelhutz AJ 2006 Human papillomavirus Type 16 E6 activates NF-kappaB, induces cIAP-2 expression, and protects against apoptosis in a PDZ binding motif-dependent manner. Journal of Virology 80 5301-5307. (https://doi.org/10.1128/JVI.01942-05)

Jang MK, Shen K \& McBride AA 2014 Papillomavirus genomes associate with BRD4 to replicate at fragile sites in the host genome. PLoS Pathogens 10 e1004117. (https://doi.org/10.1371/journal. ppat.1004117)

Jarmuz A, Chester A, Bayliss J, Gisbourne J, Dunham I, Scott J \& Navaratnam N 2002 An anthropoid-specific locus of orphan C to U RNA-editing enzymes on Chromosome 22. Genomics 79 285-296. (https://doi.org/10.1006/geno.2002.6718)

Kanu N, Cerone MA, Goh G, Zalmas LP, Bartkova J, Dietzen M, McGranahan N, Rogers R, Law EK, Gromova I, et al. 2016 DNA replication stress mediates APOBEC3 family mutagenesis in breast cancer. Genome Biology 17 185. (https://doi.org/10.1186/s13059-0161042-9)

Kazanov MD, Roberts SA, Polak P, Stamatoyannopoulos J, Klimczak LJ, Gordenin DA \& Sunyaev SR 2015 APOBEC-induced cancer mutations are uniquely enriched in early-replicating, gene-dense, and active chromatin regions. Cell Reports 13 1103-1109. (https://doi. org/10.1016/j.celrep.2015.09.077)

Kidd JM, Newman TL, Tuzun E, Kaul R \& Eichler EE 2007 Population stratification of a common APOBEC gene deletion polymorphism. PLoS Genetics 3 e63. (https://doi.org/10.1371/journal.pgen.0030063)

Kukimoto I, Mori S, Aoyama S, Wakae K, Muramatsu M \& Kondo K 2015 Hypermutation in the $E 2$ gene of human papillomavirus type 16 in cervical intraepithelial neoplasia. Journal of Medical Virology $\mathbf{8 7}$ 1754-1760. (https://doi.org/10.1002/jmv.24215)

Kuong KJ \& Loeb LA 2013 APOBEC3B mutagenesis in cancer. Nature Genetics 45 964-965. (https://doi.org/10.1038/ng.2736)

Lamy P, Nordentoft I, Birkenkamp-Demtröder K, Thomsen MBH, Villesen P, Vang S, Hedegaard J, Borre M, Jensen JB, Høyer S, et al. 2016 Paired exome analysis reveals clonal evolution and potential therapeutic targets in urothelial carcinoma. Cancer Research 76 5894-5906. (https://doi.org/10.1158/0008-5472.CAN-16-0436)

Land AM, Law EK, Carpenter MA, Lackey L, Brown WL \& Harris RS 2013 Endogenous APOBEC3A DNA cytosine deaminase is cytoplasmic and nongenotoxic. Journal of Biological Chemistry $\mathbf{2 8 8}$ 17253-17260. (https://doi.org/10.1074/jbc.M113.458661)

Landry S, Narvaiza I, Linfesty DC \& Weitzman MD 2011 APOBEC3A can activate the DNA damage response and cause cell-cycle arrest. EMBO Reports 12 444-450. (https://doi.org/10.1038/embor.2011.46)

Law EK, Sieuwerts AM, LaPara K, Leonard B, Starrett GJ, Molan AM, Temiz NA, Vogel RI, Meijer-van Gelder ME, Sweep FCGJ, et al. 2016 The DNA cytosine deaminase APOBEC3B promotes tamoxifen resistance in ER-positive breast cancer. Science Advances 2 e1601737. (https://doi.org/10.1126/sciadv.1601737)

Lebre MC, van der Aar AMG, van Baarsen L, van Capel TMM, Schuitemaker JHN, Kapsenberg ML \& de Jong EC 2007 Human keratinocytes express functional Toll-like receptor 3, 4, 5, and 9. Journal of Investigative Dermatology 127 331-341. (https://doi. org/10.1038/sj.jid.5700530)

Lechner M \& Fenton TR 2016 The genomics, epigenomics, and transcriptomics of HPV-associated oropharyngeal cancerunderstanding the basis of a rapidly evolving disease. Advances in Genetics 93 1-56. (https://doi.org/10.1016/bs.adgen.2015.12.001)

Leonard B, Hart SN, Burns MB, Carpenter MA, Temiz NA, Rathore A, Vogel RI, Nikas JB, Law EK, Brown WL, et al. 2013 APOBEC3B upregulation and genomic mutation patterns in serous ovarian carcinoma. Cancer Research 73 7222-7231. (https://doi. org/10.1158/0008-5472.CAN-13-1753)
Leonard B, McCann JL, Starrett GJ, Kosyakovsky L, Luengas EM, Molan AM, Burns MB, McDougle RM, Parker PJ, Brown WL, et al. 2015 The PKC/NF-кB signaling pathway induces APOBEC3B expression in multiple human cancers. Cancer Research $\mathbf{7 5}$ 4538-4547. (https://doi.org/10.1158/0008-5472.CAN-15-2171-T)

Lo Cigno I, De Andrea M, Borgogna C, Albertini S, Landini MM, Peretti A, Johnson KE, Chandran B, Landolfo S \& Gariglio M 2015 The nuclear DNA sensor IFI16 acts as a restriction factor for human papillomavirus replication through epigenetic modifications of the viral promoters. Journal of Virology 89 7506-7520. (https://doi. org/10.1128/JVI.00013-15)

Long J, Delahanty RJ, Li G, Gao YT, Lu W, Cai Q, Xiang YB, Li C, Ji BT, Zheng Y, et al. 2013 A common deletion in the APOBEC3 genes and breast cancer risk. Journal of the National Cancer Institute $\mathbf{1 0 5}$ 573-579. (https://doi.org/10.1093/jnci/djt018)

Madsen P, Celis JE, Rasmussen HH, Vorum H, Anant S, Gromov P, Dumanski JP, Tommerup N, Collins JE, Wright CL, et al. 1999 Psoriasis upregulated Phorbolin-1 shares structural but not functional similarity to the mRNA-editing protein Apobec-1. Journal of Investigative Dermatology 113 162-169.

Mangeat B, Turelli P, Caron G, Friedli M, Perrin L \& Trono D 2003 Broad antiretroviral defence by human APOBEC3G through lethal editing of nascent reverse transcripts. Nature 424 99-103. (https://doi. org/10.1038/nature01709)

Martinez-Zapien D, Ruiz FX, Poirson J, Mitschler A, Ramirez J, Forster A, Cousido-Siah A, Masson M, Vande S, Podjarny A, et al. 2016 Structure of the E6/E6AP/p53 complex required for HPV-mediated degradation of p53. Nature 529 541-545. (https://doi.org/10.1038/ nature16481)

Maruyama W, Shirakawa K, Matsui H, Matsumoto T, Yamazaki H, Sarca AD, Kazuma Y, Kobayashi M, Shindo K \& Takaori-Kondo A 2016 Classical NF- $\kappa$ B pathway is responsible for APOBEC3B expression in cancer cells. Biochemical and Biophysical Research Communications 478 1466-1471. (https://doi.org/10.1016/j. bbrc.2016.08.148)

McBride AA 2017 Playing with fire: consequences of human papillomavirus DNA replication adjacent to genetically unstable regions of host chromatin. Current Opinion in Virology 26 63-68. (https://doi.org/10.1016/j.coviro.2017.07.015)

McGranahan N, Favero F, de Bruin EC, Birkbak NJ, Szallasi Z \& Swanton C 2015 Clonal status of actionable driver events and the timing of mutational processes in cancer evolution. Science Translational Medicine 7 283ra54. (https://doi.org/10.1126/ scitranslmed.aaa1408)

Mellor H \& Parker PJ 1998 The extended protein kinase C superfamily. Biochemical Journal 332 281-292. (https://doi.org/10.1042/ bj3320281)

Middlebrooks CD, Banday AR, Matsuda K, Udquim KI, Onabajo OO, Paquin A, Figueroa JD, Zhu B, Koutros S, Kubo M, et al. 2016 Association of germline variants in the APOBEC3 region with cancer risk and enrichment with APOBEC-signature mutations in tumors. Nature Genetics 48 1330-1338. (https://doi.org/10.1038/ng.3670)

Mirabello L, Yeager M, Yu K, Clifford GM, Xiao Y, Zhu B, Cullen M, Boland JF, Wentzensen N, Nelson CW, et al. 2017 HPV16 E7 genetic conservation is critical to carcinogenesis. Cell 170 1164.e6-1174.e6. (https://doi.org/10.1016/j.cell.2017.08.001)

Morganella S, Alexandrov LB, Glodzik D, Zou X, Davies H, Staaf J, Sieuwerts AM, Brinkman AB, Martin S, Ramakrishna M, et al. 2016 The topography of mutational processes in breast cancer genomes. Nature Communications 7 11383. (https://doi.org/10.1038/ ncomms11383)

Mori S, Takeuchi T, Ishii Y \& Kukimoto I 2015 Identification of APOBEC3B promoter elements responsible for activation by human papillomavirus type 16 E6. Biochemical and Biophysical Research Communications 460 555-560. (https://doi.org/10.1016/j. bbrc.2015.03.068) 
Mori S, Takeuchi T, Ishii Y, Yugawa T, Kiyono T, Nishina H \& Kukimoto I 2017 Human papillomavirus 16 E6 upregulates APOBEC3B via the TEAD transcription factor. Journal of Virology 91 e02413-16. (https:// doi.org/10.1128/JVI.02413-16)

Munger K \& Jones DL 2015 Human papillomavirus carcinogenesis: an identity crisis in the retinoblastoma tumor suppressor pathway. Journal of Virology 89 4708-4711. (https://doi.org/10.1128/ JVI.03486-14)

Mussil B, Suspène R, Aynaud MM, Gauvrit A, Vartanian JP \& WainHobson S 2013 Human APOBEC3A isoforms translocate to the nucleus and induce DNA double strand breaks leading to cell stress and death. PLOS ONE 8 e73641. (https://doi.org/10.1371/journal. pone.0073641)

Nakaya Y, Stavrou S, Blouch K, Tattersall P \& Ross SR 2016 In vivo examination of mouse APOBEC3- and human APOBEC3A- and APOBEC3G-mediated restriction of parvovirus and herpesvirus infection in mouse models. Journal of Virology 90 8005-8012. (https://doi.org/10.1128/JVI.00973-16)

Narvaiza I, Linfesty DC, Greener BN, Hakata Y, Pintel DJ, Logue E, Landau NR \& Weitzman MD 2009 Deaminase-independent inhibition of parvoviruses by the APOBEC3A cytidine deaminase. PLoS Pathogens 5 e1000439. (https://doi.org/10.1371/journal. ppat.1000439)

Nees M, Geoghegan JM, Hyman T, Frank S, Miller L \& Woodworth CD 2001 Papillomavirus type 16 oncogenes downregulate expression of interferon-responsive genes and upregulate proliferation-associated and NF-kappaB-responsive genes in cervical keratinocytes. Journal of Virology 75 4283-4296. (https://doi.org/10.1128/JVI.75.9.42834296.2001)

Newman ENC, Holmes RK, Craig HM, Klein KC, Lingappa JR, Malim MH \& Sheehy AM 2005 Antiviral function of APOBEC3G can be dissociated from cytidine deaminase activity. Current Biology $\mathbf{1 5}$ 166-170. (https://doi.org/10.1016/j.cub.2004.12.068)

Newton AC 2003 Regulation of the ABC kinases by phosphorylation: protein kinase C as a paradigm. Biochemical Journal 370 361-371. (https://doi.org/10.1042/BJ20021626)

Ng JCF, Quist J, Grigoriadis A, Malim MH \& Fraternali F 2019 Pancancer transcriptomic analysis dissects immune and proliferative functions of APOBEC3 cytidine deaminases. Nucleic Acids Research $\mathbf{4 7}$ 1178-1194. (https://doi.org/10.1093/nar/gky1316)

Nikkilä J, Kumar R, Campbell J, Brandsma I, Pemberton HN, Wallberg F, Nagy K, Scheer I, Vertessy BG, Serebrenik AA, et al. 2017 Elevated APOBEC3B expression drives a kataegic-like mutation signature and replication stress-related therapeutic vulnerabilities in p53-defective cells. British Journal of Cancer 117 113-123. (https://doi.org/10.1038/ bjc.2017.133)

Nik-Zainal S, Alexandrov LB, Wedge DC, Van Loo P, Greenman CD, Raine K, Jones D, Hinton J, Marshall J, Stebbings LA, et al. 2012a Mutational processes molding the genomes of 21 breast cancers. Cell 149 979-993. (https://doi.org/10.1016/j.cell.2012.04.024)

Nik-Zainal S, Van Loo P, Wedge DC, Alexandrov LB, Greenman CD, Lau KW, Raine K, Jones D, Marshall J, Ramakrishna M, et al. 2012b The life history of 21 breast cancers. Cell 149 994-1007. (https://doi. org/10.1016/j.cell.2012.04.023)

Nik-Zainal S, Wedge DC, Alexandrov LB, Petljak M, Butler AP, Bolli N, Davies HR, Knappskog S, Martin S, Papaemmanuil E, et al. 2014 Association of a germline copy number polymorphism of APOBEC3A and APOBEC3B with burden of putative APOBEC-dependent mutations in breast cancer. Nature Genetics 46 487-491. (https://doi. org/10.1038/ng.2955)

Nordentoft I, Lamy P, Birkenkamp-Demtröder K, Shumansky K, Vang S, Hornshøj H, Juul M, Villesen P, Hedegaard J, Roth A, et al. 2014 Mutational context and diverse clonal development in early and late bladder cancer. Cell Reports 7 1649-1663. (https://doi.org/10.1016/j. celrep.2014.04.038)
Ojesina AI, Lichtenstein L, Freeman SS, Pedamallu CS, Imaz Rosshandler I, Pugh TJ, Cherniack AD, Ambrogio L, Cibulskis K, Bertelsen B, et al. 2014 Landscape of genomic alterations in cervical carcinomas. Nature 506 371-375. (https://doi.org/10.1038/ nature12881)

Okazaki IM, Hiai H, Kakazu N, Yamada S, Muramatsu M, Kinoshita K \& Honjo T 2003 Constitutive expression of AID leads to tumorigenesis. Journal of Experimental Medicine 197 1173-1181. (https://doi. org/10.1084/jem.20030275)

Okeoma CM, Lovsin N, Peterlin BM \& Ross SR 2007 APOBEC3 inhibits mouse mammary tumour virus replication in vivo. Nature $\mathbf{4 4 5}$ 927-930. (https://doi.org/10.1038/nature05540)

Okeoma CM, Petersen J \& Ross SR 2009 Expression of murine APOBEC3 alleles in different mouse strains and their effect on mouse mammary tumor virus infection. Journal of Virology 83 3029-3038. (https://doi.org/10.1128/JVI.02536-08)

Olson ME, Harris RS \& Harki DA 2018 APOBEC enzymes as targets for virus and cancer therapy. Cell Chemical Biology 25 36-49. (https:// doi.org/10.1016/j.chembiol.2017.10.007)

Papp H, Czifra G, Lázár J, Gönczi M, Csernoch L, Kovács L \& Bíró T 2003 Protein kinase $\mathrm{C}$ isozymes regulate proliferation and high cell density-mediated differentiation in HaCaT keratinocytes. Experimental Dermatology 12 811-824. (https://doi. org/10.1111/j.0906-6705.2003.00097.x)

Periyasamy M, Patel H, Lai CF, Nguyen VTM, Nevedomskaya E, Harrod A, Russell R, Remenyi J, Ochocka AM, Thomas RS, et al. 2015 APOBEC3B-mediated cytidine deamination is required for estrogen receptor action in breast cancer. Cell Reports 13 108-121. (https:// doi.org/10.1016/j.celrep.2015.08.066)

Periyasamy M, Singh AK, Gemma C, Kranjec C, Farzan R, Leach DA, Navaratnam N, Pálinkás HL, Vertessy BG, Fenton TR, et al. 2017 P53 controls expression of the DNA deaminase APOBEC3B to limit its potential mutagenic activity in cancer cells. Nucleic Acids Research 45 11056-11069. (https://doi.org/10.1093/nar/gkx721)

Petersen-Mahrt SK, Harris RS \& Neuberger MS 2002 AID mutates E. coli suggesting a DNA deamination mechanism for antibody diversification. Nature 418 99-103. (https://doi.org/10.1038/ nature00862)

Pett MR, Herdman MT, Palmer RD, Yeo GSH, Shivji MK, Stanley MA \& Coleman N 2006 Selection of cervical keratinocytes containing integrated HPV16 associates with episome loss and an endogenous antiviral response. PNAS 103 3822-3827. (https://doi.org/10.1073/ pnas.0600078103)

Qi G, Xiong H \& Zhou C 2014 APOBEC3 deletion polymorphism is associated with epithelial ovarian cancer risk among Chinese women. Tumour Biology 35 5723-5726. (https://doi.org/10.1007/ s13277-014-1758-7)

Qin T, Zhang Y, Zarins KR, Jones TR, Virani S, Peterson LA, McHugh JB, Chepeha D, Wolf GT, Rozek LS, et al. 2018 Expressed HNSCC variants by HPV-status in a well-characterized Michigan cohort. Scientific Reports 8 11458. (https://doi.org/10.1038/s41598-01829599-w)

Ramirez M, Rajaram S, Steininger RJ, Osipchuk D, Roth MA, Morinishi LS, Evans L, Ji W, Hsu CH, Thurley K, et al. 2016 Diverse drug-resistance mechanisms can emerge from drug-tolerant cancer persister cells. Nature Communications 7 10690. (https://doi. org/10.1038/ncomms10690)

Rasmussen HH \& Celis JE 1993 Evidence for an altered protein kinase C (PKC) signaling pathways in psoriasis. Journal of Investigative Dermatology 101 560-566. (https://doi.org/10.1111/1523-1747. ep12365986)

Rector A, Lemey P, Tachezy R, Mostmans S, Ghim SJ, Van Doorslaer K, Roelke M, Bush M, Montali RJ, Joslin J, et al. 2007 Ancient papillomavirus-host co-speciation in Felidae. Genome Biology 8 R57. (https://doi.org/10.1186/gb-2007-8-4-r57) 
Reinson T, Henno L, Toots M, Ustav M \& Ustav M 2015 The cell cycle timing of human papillomavirus DNA replication. PLOS ONE 10 e0131675. (https://doi.org/10.1371/journal.pone.0131675)

Richardson H, Kelsall G, Tellier P, Voyer H, Abrahamowicz M, Ferenczy A, Coutlée F \& Franco EL 2003 The natural history of typespecific human papillomavirus infections in female university students. Cancer Epidemiology, Biomarkers and Prevention 12 485-490.

Richardson SR, Narvaiza I, Planegger RA, Weitzman MD \& Moran JV 2014 APOBEC3A deaminates transiently exposed single-strand DNA during LINE-1 retrotransposition. ELife 3 e02008. (https://doi. org/10.7554/eLife.02008)

Rigoni-Stern D 1842 Fatti statistici relativi alle malattie cancerose. Giornale Progresos Patolégica Terapija 2 507-517.

Riley RR, Duensing S, Brake T, Münger K, Lambert PF \& Arbeit JM 2003 Dissection of human papillomavirus E6 and E7 function in transgenic mouse models of cervical carcinogenesis. Cancer Research 63 4862-4871.

Roberts SA, Lawrence MS, Klimczak LJ, Grimm SA, Fargo D, Stojanov P, Kiezun A, Kryukov GV, Carter SL, Saksena G, et al. 2013 An APOBEC cytidine deaminase mutagenesis pattern is widespread in human cancers. Nature Genetics 45 970-976. (https://doi.org/10.1038/ ng.2702)

Rogozin IB, Roche-Lima A, Lada AG, Belinky F, Sidorenko IA, Glazko GV, Babenko VN, Cooper DN, Pavlov YI 2019 Nucleotide weight matrices reveal ubiquitous mutational footprints of AID/APOBEC deaminases in human cancer genomes. Cancers 11 211. (https://doi.org/10.3390/ cancers11020211)

Sakakibara N, Chen D \& McBride AA 2013 Papillomaviruses use recombination-dependent replication to vegetatively amplify their genomes in differentiated cells. PLoS Pathogens 9 e1003321. (https:// doi.org/10.1371/journal.ppat.1003321)

Scheffner M, Huibregtse JM, Vierstra RD \& Howley PM 1993 The HPV16 E6 and E6-AP complex functions as a ubiquitin-protein ligase in the ubiquitination of p53. Cell 75 495-505. (https://doi. org/10.1016/0092-8674(93)90384-3)

Schreiber RD, Old LJ \& Smyth MJ 2011 Cancer immunoediting: integrating immunity's roles in cancer suppression and promotion. Science 331 1565-1570. (https://doi.org/10.1126/science.1203486)

Seo HR, Kwan YW, Cho CK, Bae S, Lee SJ, Soh JW, Chung HY \& Lee YS 2004 PKC $\alpha$ induces differentiation through ERK1/2 phosphorylation in mouse keratinocytes. Experimental and Molecular Medicine 36 292-299. (https://doi.org/10.1038/emm.2004.40)

Seplyarskiy VB, Soldatov RA, Popadin KY, Antonarakis SE, Bazykin GA \& Nikolaev SI 2016 APOBEC-induced mutations in human cancers are strongly enriched on the lagging DNA strand during replication. Genome Research 26 174-182. (https://doi.org/10.1101/ gr.197046.115)

Shalem O, Sanjana NE \& Zhang F 2015 High-throughput functional genomics using CRISPR-Cas9. Nature Reviews Genetics 16 299-311. (https://doi.org/10.1038/nrg3899)

Sharma S, Patnaik SK, Taggart RT, Kannisto ED, Enriquez SM, Gollnick P \& Baysal BE 2015 APOBEC3A cytidine deaminase induces RNA editing in monocytes and macrophages. Nature Communications 6 6881. (https://doi.org/10.1038/ncomms7881)

Sheehy AM, Gaddis NC, Choi JD \& Malim MH 2002 Isolation of a human gene that inhibits HIV-1 infection and is suppressed by the viral Vif protein. Nature 418 646-650. (https://doi.org/10.1038/ nature00939)

Shi K, Carpenter MA, Banerjee S, Shaban NM, Kurahashi K, Salamango DJ, McCann JL, Starrett GJ, Duffy JV, Demir Ö, et al. 2017 Structural basis for targeted DNA cytosine deamination and mutagenesis by APOBEC3A and APOBEC3B. Nature Structural and Molecular Biology 24 131-139. (https://doi.org/10.1038/nsmb.3344)

Sieuwerts AM, Willis S, Burns MB, Look MP, Gelder MEM-V, Schlicker A, Heideman MR, Jacobs H, Wessels L, Leyland-Jones B, et al. 2014 Elevated APOBEC3B correlates with poor outcomes for estrogen- receptor-positive breast cancers. Hormones and Cancer 5 405-413. (https://doi.org/10.1007/s12672-014-0196-8)

Silvas TV, Hou S, Myint W, Nalivaika E, Somasundaran M, Kelch BA, Matsuo H, Kurt Yilmaz N \& Schiffer CA 2018 Substrate sequence selectivity of APOBEC3A implicates intra-DNA interactions. Scientific Reports 8 7511. (https://doi.org/10.1038/s41598-018-25881-z) Siriwardena SU, Perera MLW, Senevirathne V, Stewart J \& Bhagwat AS 2018 A tumor-promoting phorbol ester causes a large increase in APOBEC3A expression and a moderate increase in APOBEC3B expression in a normal human keratinocyte cell line without increasing genomic uracils. Molecular and Cellular Biology 39 e0023818. (https://doi.org/10.1128/MCB.00238-18)

Stanley MA, Browne HM, Appleby M \& Minson AC 1989 Properties of a non-tumorigenic human cervical keratinocyte cell line. International Journal of Cancer 43 672-676. (https://doi.org/10.1002/ ijc.2910430422)

Starrett GJ, Luengas EM, McCann JL, Ebrahimi D, Temiz NA, Love RP, Feng Y, Adolph MB, Chelico L, Law EK, et al. 2016 The DNA cytosine deaminase APOBEC3H haplotype I likely contributes to breast and lung cancer mutagenesis. Nature Communications 712918. (https://doi.org/10.1038/ncomms12918)

Stavrou S, Crawford D, Blouch K, Browne EP, Kohli RM \& Ross SR 2014 Different modes of retrovirus restriction by human APOBEC3A and APOBEC3G in vivo. PLoS Pathogens 10 e1004145. (https://doi. org/10.1371/journal.ppat.1004145)

Stavrou S, Zhao W, Blouch K \& Ross SR 2018 Deaminase-dead mouse APOBEC3 is an in vivo retroviral restriction factor. Journal of Virology 92. (https://doi.org/10.1128/JVI.00168-18)

Strati K, Pitot HC \& Lambert PF 2006 Identification of biomarkers that distinguish human papillomavirus (HPV)-positive versus HPVnegative head and neck cancers in a mouse model. PNAS $\mathbf{1 0 3}$ 14152-14157. (https://doi.org/10.1073/pnas.0606698103)

Suspène R, Mussil B, Laude H, Caval V, Berry N, Bouzidi MS, Thiers V, Wain-Hobson S \& Vartanian JP 2017 Self-cytoplasmic DNA upregulates the mutator enzyme APOBEC3A leading to chromosomal DNA damage. Nucleic Acids Research 45 3231-3241. (https://doi. org/10.1093/nar/gkx001)

Taylor BJ, Nik-Zainal S, Wu YL, Stebbings LA, Raine K, Campbell PJ, Rada C, Stratton MR \& Neuberger MS 2013 DNA deaminases induce break-associated mutation showers with implication of APOBEC3B and $3 \mathrm{~A}$ in breast cancer kataegis. ELife 2 e00534. (https://doi. org/10.7554/eLife.00534)

The Cancer Genome Atlas Network 2015 Comprehensive genomic characterization of head and neck squamous cell carcinomas. Nature 517 576-582. (https://doi.org/10.1038/nature14129)

Tilborghs S, Corthouts J, Verhoeven Y, Arias D, Rolfo C, Trinh XB \& van Dam PA 2017 The role of nuclear factor-kappa B signaling in human cervical cancer. Critical Reviews in Oncology/Hematology 120 141-150. (https://doi.org/10.1016/j.critrevonc.2017.11.001)

Vartanian JP, Guétard D, Henry M \& Wain-Hobson S 2008 Evidence for editing of human papillomavirus DNA by APOBEC3 in benign and precancerous lesions. Science 320 230-233. (https://doi.org/10.1126/ science.1153201)

Venkatesan S, Rosenthal R, Kanu N, McGranahan N, Bartek J, Quezada SA, Hare J, Harris RS \& Swanton C 2018 Perspective: APOBEC mutagenesis in drug resistance and immune escape in HIV and cancer evolution. Annals of Oncology 29 563-572. (https://doi. org/10.1093/annonc/mdy003)

Verlaat W, Snijders PJF, van Moorsel MIH, Bleeker M, Rozendaal L, Sie D, Ylstra B, Meijer CJLM, Steenbergen RDM \& Heideman DAM 2015 Somatic mutation in PIK3CA is a late event in cervical carcinogenesis. Journal of Pathology: Clinical Research 1 207-211. (https://doi.org/10.1002/cjp2.27)

Vieira VC, Leonard B, White EA, Starrett GJ, Temiz NA, Lorenz LD, Lee D, Soares MA, Lambert PF, Howley PM, et al. 2014 Human papillomavirus E6 triggers upregulation of the antiviral and cancer (c) 2019 Society for Endocrinology Published by Bioscientifica Ltd. Printed in Great Britain 
genomic DNA deaminase APOBEC3B. MBio 5 e02234-14. (https:// doi.org/10.1128/mBio.02234-14)

Wakae K, Aoyama S, Wang Z, Kitamura K, Liu G, Monjurul AM, Koura M, Imayasu M, Sakamoto N, Nakamura M, et al. 2015 Detection of hypermutated human papillomavirus type 16 genome by next-generation sequencing. Virology 485 460-466. (https://doi. org/10.1016/j.virol.2015.08.017)

Wakae K, Nishiyama T, Kondo S, Izuka T, Que L, Chen C, Kase K, Kitamura K, Mohiuddin M, Wang Z, et al. 2018 Keratinocyte differentiation induces APOBEC 3A, 3B, and mitochondrial DNA hypermutation. Scientific Reports 8 9745. (https://doi.org/10.1038/ s41598-018-27930-z)

Wallace NA \& Münger K 2018 The curious case of APOBEC3 activation by cancer-associated human papillomaviruses. PLoS Pathogens $\mathbf{1 4}$ e1006717. (https://doi.org/10.1371/journal.ppat.1006717)

Wang Z, Wakae K, Kitamura K, Aoyama S, Liu G, Koura M, Monjurul AM, Kukimoto I \& Muramatsu M 2014 APOBEC3 deaminases induce hypermutation in human papillomavirus 16 DNA upon beta interferon stimulation. Journal of Virology 88 1308-1317. (https://doi.org/10.1128/JVI.03091-13)

Wang S, Jia M, He Z \& Liu XS 2018 APOBEC3B and APOBEC mutational signature as potential predictive markers for immunotherapy response in non-small cell lung cancer. Oncogene 37 3924-3936. (https://doi.org/10.1038/s41388-018-0245-9)

Warren CJ, Xu T, Guo K, Griffin LM, Westrich JA, Lee D, Lambert PF, Santiago ML \& Pyeon D 2015a APOBEC3A functions as a restriction factor of human papillomavirus. Journal of Virology 89 688-702. (https://doi.org/10.1128/JVI.02383-14)

Warren CJ, Van Doorslaer K, Pandey A, Espinosa JM \& Pyeon D 2015b Role of the host restriction factor APOBEC3 on papillomavirus evolution. Virus Evolution 1 vev015. (https://doi.org/10.1093/ve/vev015)

Warren CJ, Westrich JA, Van Doorslaer KV \& Pyeon D 2017 Roles of APOBEC3A and APOBEC3B in human papillomavirus infection and disease progression. Viruses 9 1-20. (https://doi.org/10.3390/ v9080233)

Wen WX, Soo JS-S, Kwan PY, Hong E, Khang TF, Mariapun S, Lee CS-M, Hasan SN, Rajadurai P, Yip CH, et al. 2016 Germline APOBEC3B deletion is associated with breast cancer risk in an Asian multiethnic cohort and with immune cell presentation. Breast Cancer Research 18 56. (https://doi.org/10.1186/s13058-016-0717-1)

Westrich JA, Warren CJ, Klausner MJ, Guo K, Liu CW, Santiago ML \& Pyeon D 2018 Human papillomavirus 16 E7 stabilizes APOBEC3A protein by inhibiting cullin 2-dependent protein degradation. Journal of Virology 92 e01318-17. (https://doi.org/10.1128/JVI.01318-17)

Xuan D, Li G, Cai Q, Deming-Halverson S, Shrubsole MJ, Shu XO, Kelley MC, Zheng W \& Long J 2013 APOBEC3 deletion polymorphism is associated with breast cancer risk among women of European ancestry. Carcinogenesis 34 2240-2243. (https://doi. org/10.1093/carcin/bgt185)

Yamanaka S, Balestra ME, Ferrell LD, Fan J, Arnold KS, Taylor S, Taylor JM \& Innerarity TL 1995 Apolipoprotein B mRNA-editing protein induces hepatocellular carcinoma and dysplasia in transgenic animals. PNAS 92 8483-8487. (https://doi.org/10.1073/ pnas.92.18.8483)

Yang LC, Ng DC \& Bikle DD 2003 Role of protein kinase C $\alpha$ in calcium induced keratinocyte differentiation: defective regulation in squamous cell carcinoma. Journal of Cellular Physiology 195 249-259. (https://doi.org/10.1002/jcp.10248)

Zhang H, Yang B, Pomerantz RJ, Zhang C, Arunachalam SC \& Gao L 2003 The cytidine deaminase CEM15 induces hypermutation in newly synthesized HIV-1 DNA. Nature 424 94-98. (https://doi. org/10.1038/nature01707)

Zhang H, Liu CY, Zha ZY, Zhao B, Yao J, Zhao S, Xiong Y, Lei QY \& Guan KL 2009 TEAD transcription factors mediate the function of TAZ in cell growth and epithelial-mesenchymal transition. Journal of Biological Chemistry 284 13355-13362. (https://doi.org/10.1074/jbc. M900843200)

Zhao B, Ye X, Yu J, Li L, Li W, Li S, Yu J, Lin JD, Wang CY, Chinnaiyan AM, et al. 2008 TEAD mediates YAP-dependent gene induction and growth control. Genes and Development 22 1962-1971. (https://doi.org/10.1101/gad.1664408)

Zhu C, Li L \& Zhao B 2015 The regulation and function of YAP transcription co-activator. Acta Biochimica et Biophysica Sinica $\mathbf{4 7}$ 16-28. (https://doi.org/10.1093/abbs/gmu110)

Received in final form 6 March 2019

Accepted 14 March 2019

Accepted Preprint published online 14 March 2019
(C) 2019 Society for Endocrinology Published by Bioscientifica Ltd. Printed in Great Britain 